\title{
DISTRIBUTIONAL MODIFICATION: THE CASE OF FREQUENCY ADJECTIVES
}

\author{
Berit GeHrke \\ Louise McNally \\ CNRS/Université Paris Diderot \\ Universitat Pompeu Fabra
}

\begin{abstract}
We argue that DISTRIBUTIONAL MODIFICATION is one strategy that language affords for composing propositions about the quantity of entities that participate in a given situation. Distributional modifiers apply to kind descriptions, contributing the entailment that the kind is instantiated by a SET of tokens with a particular distribution. As a case study, we analyze frequency adjectives (FAs, e.g. occasional). We show that previous work, including our own, has suffered for focusing on the paraphrases of FAs rather than on their morphosyntax. We argue for two subclasses of FAs: those that are intersective modifiers sortally restricted to events, and those that are not. The study reinforces two novel theoretical claims in Gehrke \& McNally 2011: sometimes kinds are realized by sets of tokens, rather than individual tokens; and some clauses constitute descriptions of EVENT KINDS, rather than EVENT TOKENS.*
\end{abstract}

Keywords: semantics, modification, adjectives, events, kinds, quantification

1. InTRODUCTION. Natural language affords various strategies for composing propositions about the quantity of entities that participate in a given event or have a given property. Perhaps the most familiar is quantification. The classic analysis of quantificational determiners (Barwise \& Cooper 1981) treats them as relations between sets. For example, most in 1a compares the number of individuals that are birds and fly with the number of individuals that are birds and do not fly; if the former is larger than the latter, 1a is true. ${ }^{1}$ A similar kind of comparison is possible with eventualities or times, as exemplified in 1b. Though the details of the analyses differ, de Swart (1993) and others have argued that, in a sentence like 1b, the adverb always compares the set of events or times in which Mary thinks it is going to rain with the set of events or times in which she carries an umbrella. Example $1 b$ is true if the former is a subset of the latter.

(1) a. Most birds fly.

b. Mary always carries an umbrella if she thinks it is going to rain.

A second strategy for formulating propositions expressing quantity involves modification: quantities can be conceived of as properties of masses or sets. ${ }^{2}$ For example, two in $2 \mathrm{a}$ can be analyzed as contributing the property that the cardinality of the set of birds referred to is two (Milsark 1974). Similar analyses can be given for vague expressions such as many or some, as in $2 \mathrm{~b}$.

(2) a. two birds

b. some rain

Carlson's 1977 analysis of certain generic sentences points to a third strategy for expressing propositions about quantity. Carlson argued that the bare plural in 3 refers to a

* We gratefully acknowledge the comments we received from the audiences at the 2009 and 2012 SALT conferences; the GLOW 32 Semantics Workshop on Modes of Composition; the 2010 GENIUS Workshop on Dispositions, Abilities, and States; Sinn und Bedeutung 18; and the 2013 Tbilisi Symposium on Logic, Language and Computation; as well as from audiences in Barcelona, Düsseldorf, Paris, and Utrecht. This work has been supported by grants HUM2007-60599, FFI2010-15006, FFI2013-41301-P, and JCI-2010-08581 from the Spanish Ministry of Education and Science, as well as by an ICREA Foundation Academia award to the second author.

${ }^{1}$ This sentence has another interpretation expressing a generalization of the same form about subkinds of birds. This does not affect the point being made here.

${ }^{2}$ Whether proportions can also be conceived of as simple properties is less obvious, as these inherently involve a comparison of a full set with a subset of itself. To a large extent, proportional determiners fail to show the modifier-like behavior that nonproportional determiners do; however, there are some exceptions. See Barwise \& Cooper 1981, Keenan \& Stavi 1986, and McNally 1998 for further discussion. 
natural kind — an abstract entity — just as a proper name refers to a unique individual. He argued that sentences like 3, despite expressing generalizations that carry implications about quantity, should not be analyzed as comparing sets. Rather, their propositional structure simply involves predication of a property (in this case, that of flying) to a kind entity (in this case, the kind BIRD). In order for it to be true for the property of flying to hold of birds as a kind, an appropriate number of token birds must fly.

(3) Birds fly.

Gehrke \& McNally 2011, developing a proposal in Schäfer 2007, argues that there is yet a fourth strategy, which is a variation on the modifier strategy. We find it exemplified in sentences like those in $4 \mathrm{a}$, which involve a subset of the so-called FREQUENCY ADJECTIVES (FAs), notably occasional, odd, and rare (see also Bolinger 1967, Stump 1981, Larson 1998, Zimmermann 2003). ${ }^{3}$

(4) a. The occasional sailor strolled by.

(Bolinger 1967)

b. OSM does not have building footprints for Grand Rapids (except for the odd building). ${ }^{4}$

c. Their propaganda did its work, and in several years only the rare person in Russia could remember that the United States had its own peace program ...

(COCA)

These sentences provide information about the distribution of sailors, buildings, and Russians, respectively, in certain kinds of situations or locations. Gehrke \& McNally 2011 argues that the FAs in these sentences denote properties not of sets of individuals but crucially of descriptions of kinds. The FA contributes the entailment that the kind description in question is instantiated not by a single token but rather by a SET of tokens and that, moreover, these must have a particular sort of distribution. For example, $4 \mathrm{a}$ entails that the kind SAILOR is realized in the context by a set of token sailors with a low distribution. As we explain below, this analysis carries with it an interesting corollary, namely that sentences such as 4a constitute propositions about event KINDS (or TYPESwe use the terms interchangeably here) rather than event TOKENS. ${ }^{5}$

A significant amount of research has already been devoted to identifying the theoretical and empirical differences between the first three of these strategies, and to evaluating their pros and cons as analyses for specific natural language data. The fourth has not yet been the focus of detailed study. The main contribution of this article is to address this gap via a more detailed and empirically adequate study of the FAs in 4 and others, such as frequent, sporadic, and daily, than the study provided in Gehrke \& McNally 2011.

The behavior of FAs is highly complex, and all previous analyses have left a number of facts unexplained. We attribute this to the fact that these analyses have been shaped more by the paraphrases that have been identified for FAs (treated in the literature as three different readings - the internal, generic, and adverbial - as illustrated in the following section) rather than by the morphosyntactic behavior they manifest. In what follows, we show that concentrating on the three putative readings is misleading, and we instead focus on a more systematic description of the morphosyntax of FAs together

\footnotetext{
${ }^{3}$ As part of our study we have extracted examples from the British National Corpus (BNC), the Corpus of Contemporary American English (COCA), the Corpus of Global Web-Based English (GloWbE), and the Google Books corpus of American English, all available at http://corpus.byu.edu; we have obtained others from Google searches. Examples from the corpus.byu.edu site will be identified simply by the name of the source corpus; examples from Google searches will be identified by their full URL in a footnote.

4 http://gis.stackexchange.com/questions/53718/where-how-can-i-find-buy-make-building-footprints-for -kent-county-mi-grand-rap

${ }^{5}$ We use the term EVENT in the most general sense to include states as well.
} 
with the corresponding interpretations. This description reveals that FAs fall into two distinct subclasses - those that are specifically temporal and those that are not - each of which contributes entailments about distribution in a different way, though they both involve modification.

The article is structured as follows. An overview of the data is provided first (§2), including additional evidence from German for dividing FAs into two subclasses. We then present the analysis in $\S 3$, adopting the proposal in Gehrke \& McNally 2011 for one subclass of FAs but not the other, though both subclasses are effectively analyzed as adjectival modifiers. Finally, the advantages of the proposed analysis over previous accounts are discussed in $\S 4$.

2. EMPIRICAL OBSERVATIONS. Our first task is to argue that what is crucial to understanding the data is whether a given FA is a temporal predicate. ${ }^{6}$ If it is temporal, it is restricted to characterizing the distribution of events, as opposed to being (additionally or exclusively) used to express some kind of nontemporal distribution. On the nontemporal use, first identified, to our knowledge, in Stump 1981 with an example similar to 5a, the individuals in question can be temporally colocated as long as they are properly distributed over some other sort of contextually identified domain (typically space). We add further examples from different corpora to illustrate nontemporal distribution with occasional (5b), odd (6), and rare (7). ${ }^{7}$

(5) a. The occasional sailor is 6 feet tall.

b. After a long trek, you and your band of friends arrive at a grey-brown wasteland. a plain filled with nothing but the occasional hill, a large plateau, and a ruined castle.$^{8}$

(6) a. It's in a room crowded with gauges and microscopes, along with the odd bicycle and Congo drum, on a leafy campus surrounded by Washington, D.C.'s Rock Creek Park.

(COCA)

b. In the middle of all this life is a featureless landscape: the occasional twoor three-story apartment building, put up in the twenties, when it was thought that people in this city would wish to live in apartments; a glimpse of commerce - the odd office, barbershop, or Vietnamese strip mall; some abandoned developments.

(COCA)

(7) a. In 1959 and 1960 it was a different world than it is now. There was the rare female engineer, but we weren't really guided or encouraged to go into other careers. ${ }^{9}$

\footnotetext{
${ }^{6}$ The set of FAs we study is drawn from the literature. FAs have been lexically classified according to whether they express a fixed frequency (e.g. daily, weekly, monthly, yearly) or a relative, contextually determined frequency (e.g. occasional, sporadic, periodic, odd, rare, infrequent, frequent). Within the category of relative-frequency adjectives, some authors (e.g. Larson 1998, Zimmermann 2003) have distinguished between two subgroups according to whether they describe frequency or infrequency, on the basis of apparent differences in distribution between them. Since our examination of the data has revealed that these distinctions, while not completely irrelevant, are not helpful in getting at the core generalizations, we largely abstract away from them here.

${ }^{7}$ Not all speakers we have consulted find 5a very felicitous. However, we mention it because it is cited in the literature. In any event, as 5b, 6, and 7 show, other examples making the same point are attested. An anonymous referee suggests that the oddness of 5 a might be due to the fact that the property of being tall is not spatially anchored, making it difficult to ensure that the distribution conditions contributed by the FA are met. This seems like a plausible hypothesis to us, but we must leave (dis)confirmation of it for future research.

${ }^{8} \mathrm{http}: / /$ musescore.com/user/100240/scores/114572

${ }^{9} \mathrm{http} / /$ quest.arc.nasa.gov/space/frontiers/ohara.html
} 
b. [He'll look back to] those caddieing days, his only burden someone else's 30-pound bag over his right shoulder, arriving hot and hungry at a halfway house. 'There were some guys who would let you get a soda,' Dunne says. 'There were some guys who let you get a soda and a hot dog. And there was the rare guy who would let you get a soda and a hamburger.' 10

Stump observed that this interpretation is not available to FAs that express fixed frequency, like weekly, but he did not observe that in fact it is unavailable with any of the FAs in 8 .

(8) ??a glimpse of commerce-the weekly/frequent/infrequent/periodic/sporadic office, barbershop, or Vietnamese strip mall ...

We show in $\$ 2.2$ that the temporal/nontemporal distinction correlates with various morphosyntactic properties and supports our claims about these generalizations. Before doing so, however, we devote $\S 2.1$ to briefly reviewing the paraphrase-based perspective on FAs from the previous literature, adding a few observations of our own. We do this for two reasons. First, it will facilitate comparisons between previous analyses and the one we eventually develop. Second, it will make clear why we shift to the perspective that is focused on the FAs themselves and the sorts of nominals they combine with.

2.1. The three PUtATIVE READINGS of FAs. Based on different paraphrases available for FAs, previous analyses have identified three different readings: the internal, the generic, and the adverbial. We show that the paraphrases associated with some of the readings can in fact come about in more than one way. For this reason these paraphrases prove to offer less insight into the proper analysis of FAs than does their peculiar morphosyntactic behavior, which we also describe below.

THE INTERNAL READING. Under the internal reading, illustrated in 9, the semantic effect of the FA is clearly limited to the DP in which it appears, and a possible paraphrase of [FA N] is 'N who/that V's/is V'd FA-ly'.

(9) a. A frequent sailor (= one who sails frequently) won the regatta.

b. A frequent recipient of awards (= one who frequently receives awards) took the Rotary Club prize again.

Intuitively, under this reading, the nominal describes an individual who participates in the sort of event lexically associated with that nominal (for example, for sailor in 9a, sailing) and whose identity is stable across the eventualities that support the applicability of the FA. The FA specifies the frequency with which those eventualities occur. Thus, the internal reading is most naturally perceivable with participant nouns, as in $9 .{ }^{11}$ In contrast, event nouns (10a) and sortal nouns (10b) generally do not allow the internal reading, as can be seen by the unacceptable paraphrases in 10 .

(10) a. a frequent visit $\neq$ a particular visit that happens frequently

b. a frequent letter $\neq$ a particular letter that V's/is V'd frequently

The fact that the constituent formed by the FA and the noun has to describe a particular individual in order for the internal reading to arise makes the internal reading im-

\footnotetext{
${ }^{10} \mathrm{http}$ //www.golfdigest.com/golf-tours-news/2011-09/golf-fields-rosaforte-911 c currentPage=5

${ }^{11}$ For reasons that will soon be evident, we distinguish three classes of nouns that FAs combine with: participant-denoting nouns (e.g. recipient, sailor, employee), eventuality-denoting nouns (e.g. visit, swimming, discussion), and all other nouns (e.g. beer, car, chair; this latter class is defined negatively as all nouns that are not derived from verbs and/or cannot name events or participants in events). We use the descriptive labels PARTICIPANT NOUNS, EVENT NOUNS, and SORTAL NOUNS for these classes, respectively.
} 
plausible for event nouns that describe token events: a token event occurs only once in time and thus will not be manifest on multiple occasions, as the truth conditions contributed by the FA on the internal reading require. In the case of sortal nouns, we attribute the lack of internal reading to the fact that, unlike participant nouns, their semantics does not entail participation (in the real world or some possible world) in any particular sort of eventuality. A similar sort of contrast has already been argued by Winter and Zwarts (2012) to account for the fact that beautiful can describe Olga's dancing in 11a, where dancer is a participant nominal, but not Olga's artistic activity in $11 \mathrm{~b}$.

(11) a. Olga is a beautiful dancer. = Olga dances beautifully.

b. Olga is a beautiful artist. $\neq$ Olga produces art beautifully.

Winter and Zwarts (refining a proposal in Larson 1998) argue that dancer can make available an event argument for modification because it is deverbal, but (in contrast to Larson) that artist cannot because it does not have an analogous way to make such an argument available. So-called stage nouns (Gupta 1980, Carlson 1982), such as batter, passenger, guest, and customer, also behave like deverbal participant nouns. Stage nouns are not necessarily deverbal, but they have been argued to apply crucially to stages or spatiotemporal slices of individuals (see Carlson 1977 on stages). The similarity with deverbal participant nouns is expected insofar as it is possible to recast the idea of a spatiotemporal slice of an individual as a relation between an individual and an event.

The internal reading is sensitive not only to the type of noun modified, but also to the FA itself. Though generally acceptable with all FAs (12), there are two exceptions. First, it is completely excluded with odd (13).

(12) a. a daily/weekly Internet user = one who uses the Internet daily/weekly

b. a frequent/infrequent/sporadic/periodic visitor= one who visits frequently/ infrequently/sporadically/periodically

c. $a(n)$ occasional reader of the newspaper $=$ one who reads the newspaper occasionally

(13) an odd user/visitor/reader $\neq$ one who uses/visits/reads on odd occasions

Second, with rare the reading is limited to participant or stage nouns that entail a location relation or specify one explicitly: contrast 14 and 15. A survey of all of the noun lemmata occurring with rare in the COCA corpus (1,973 hits, forty-seven participant or stage nouns) revealed only one clear example of the internal reading with visitor and one with contributor; a Google search uncovered a few additional examples with other nouns.

(14) a. a rare writer $\neq$ one who writes rarely

b. a rare employee $\neq$ one who is employed rarely

c. a rare winner $\neq$ one who wins rarely

(15) a. Even though we were living in a Philadelphia apartment surrounded by gyms, basketball courts, and riverside bike paths, I' $\mathrm{d}$ become a rare visitor to any of them

b. [he] was a rare contributor to Macmillan's ...

c. The impression I get as quite a rare passenger on mainline charters is that ... 12

d. he was a rare customer and it was definitely surprising when he did come in.

(Google; current URL unavailable)

\footnotetext{
12 https://www.national-preservation.com/threads/come-in-mk1-your-time-is-up.20350/page-3
} 
As is discussed in $\$ 3.2$ below, we consider this a distinct use of rare on which it has an additional (often unexpressed) argument that indicates the spatial or temporal domain within which the kind of individual described by the noun is distributed. No previous analysis of FAs has accounted for the lexical variation in 12-15.

Another distinguishing characteristic of the internal reading is that it is compatible with any determiner; see 16 .

(16) A/Some/One/The/That/Each frequent sailor I know owns his own boat.

In this latter respect the internal reading sharply contrasts with both the generic and the adverbial readings, to which we now turn.

The Generic Reading. According to both Stump (1981) and Schäfer (2007), the generic reading is possible with all kinds of [FA N] combinations, and it naturally arises when the DP containing the FA is an argument to a generic predicate, as in 17.

(17) a. A(n) monthly/frequent/occasional check-up is essential.

b. A(n) yearly/infrequent/rare visitor is not a problem.

c. A daily/sporadic cup of coffee is harmless.

d. The odd glitch is tolerable.

e. ... there is little evidence to show that the rare drink will impair the healthy growth of a baby. ${ }^{13}$

Stump identifies this reading by paraphrase, observing that the FA in such sentences can be substituted with a postnominal modifier such as now and then, from time to time, and every day. ${ }^{14}$

(18) a. A check-up on a monthly/frequent/occasional basis is essential.

b. A visitor on a yearly/infrequent basis is not a problem.

c. A cup of coffee on a sporadic basis is harmless.

d. A glitch on odd occasions is tolerable.

e. A drink on rare occasions will (not) impair the healthy growth of a baby.

With episodic (Carlson's (1977) stage-level) predicates, the FA is either unacceptable or is not paraphrasable as in 18 ; see $19 .{ }^{15}$

(19) a. ??An occasional cup of coffee has left circular stains on the table.

(Stump 1981)

b. The Premier Division-based Scotland side were only beaten, in fact, by a goal of almost tragic proportions, conceded when an infrequent error was characteristically punished by Riedle. $\neq$ An error on an infrequent basis was characteristically punished by Riedle.

\footnotetext{
${ }^{13} \mathrm{http}$ ://answers.yahoo.com/question/index?qid=20110501003637AAeLyDj

${ }^{14}$ Stump does not explicitly paraphrase examples using, for example, on a [FA] basis, but this sort of paraphrase is in the spirit of his claims.

${ }^{15}$ Stump also describes as generic a use of the FA that he claims is restricted to definite nominals (including possessive-marked ones) and that is found with episodic predicates.
}

(i) John's occasional cup of coffee had left circular stains on the table.

Stump took the subject of (i) to denote an object that realizes the kind of individual that is a cup of coffee drunk by John now and then. He classified this use of the FA as generic because it involves the same basic semantics for the FA as the one he used for examples like those in 17 and it contrasted with his analysis of the FA on the adverbial reading. We consider Stump's account of this example to be essentially correct, but we suspect that the FA functions here as a nonrestrictive modifier, rather than as a restrictive modifier (see e.g. Potts 2005 for diagnostics to distinguish the two sorts of modifiers). We focus exclusively on restrictive uses of FAs in this article. 
Though the nuances of his discussion are complex, Stump observes that the generic reading arises when the nominal is interpretable as generic independently of the presence of the FA. Our analysis will coincide with Stump's on this point. For example, the following sentences are generic, even in the absence of the FA.

(20) a. A check-up is essential.

b. A visitor is not a problem.

c. A cup of coffee is harmless.

Similarly, the sentences in 19 are not generic when the FA is removed. Moreover, this parallelism extends to bare plurals: the following are generic both with and without the FA.

(21) a. (Frequent) check-ups are essential.

b. (Infrequent) visitors are not a problem.

c. (Daily) cups of coffee are harmless.

We therefore conclude that, in examples like $17 \mathrm{a}-\mathrm{c}$, the FA plays no crucial role in determining whether the sentence has or does not have a generic reading.

If the genericity of these sentences is independent of the FA, we predict that the determiners that appear with the different FAs should be exactly those that appear in the corresponding generic sentences without the FAs. Schäfer (2007) argues that this is, in fact, the case. He claims that the generic reading is compatible only with the definite and indefinite articles and semantically bleached possessives, as shown by contrasts such as that between $22 \mathrm{a}$ and $22 \mathrm{~b}, \mathrm{c.}{ }^{16}$

(22) a. An/The/Your occasional beer is good for you.

b. ??Each occasional beer is good for you.

c. ??Two/??Many occasional beers are good for you.

The sentences in 22b,c lack a generic reading without the FA (why they are odd and not simply given a different interpretation will become clear in $\S 3$ ).

However, Schäfer did not observe that, in fact, the use of determiners is more restricted than this: the only FA that behaves as in 22a in accepting all three (but none of the other) determiners is occasional. All other FAs that readily appear with the indefinite article as in 17 ( frequent, daily, etc.) are highly marked with the definite article or bleached possessive (see 23).

(23) a. ??The/??Your daily shower is good for you.

b. ??The/??Your infrequent/frequent beer is good for you.

c. ??The/??Your sporadic/periodic inspection is necessary.

The facts in 23 are consistent with what we have seen so far, insofar as these sentences lack a generic reading without the FA (again, we might wonder why they are odd, as opposed to simply having a nongeneric interpretation; see §3.1). As is well known, in English only certain sorts of well-established kinds can be referred to using a singular definite description, as illustrated in 24 (examples from Carlson 2009; see also Carlson 1977, Krifka et al. 1995, Dayal 2004).

\footnotetext{
${ }^{16}$ Stump (1981), by contrast, claims that the generic reading is compatible with a full range of determiners, as he considers generic examples such as the following.

(i) a. No daily news program can match this one.

b. John agreed to conduct one weekly inspection a year.

Note that (ib) is not a generic sentence, however, and we consider Schäfer's observation concerning the determiner restriction an important insight. The examples in (i) have a natural account on our analysis, as we show in $\$ 3.1$.
} 
(24) The ??green/Coke bottle has a narrow neck.

(cp. Green bottles have narrow necks.)

By contrast, things are very different with odd and rare. The sort of interpretation that can be paraphrased as in 18 is systematically available for these FAs only in combination with the definite article or bleached possessive, and not with the indefinite article or bare plural; see the contrast between $17 \mathrm{~d}$,e and 25 .

(25) a. An odd glitch is/Odd glitches are tolerable. $\neq$ The occurrence of glitches on odd occasions is tolerable.

b. A rare drink/Rare drinks will not impair the healthy growth of a baby. $\neq \mathrm{A}$ drink on rare occasions will not impair the healthy growth of a baby.

Moreover, the generic reading in $17 \mathrm{~d}$,e, like that when occasional occurs with the definite article, is possible despite the fact that the corresponding sentences without the FA lack a generic reading.

(26) a. The glitch is tolerable.

b. The drink will not impair the healthy growth of a baby.

c. The beer is good for you.

Clearly, something very different is going on with odd, rare, and this use of occasional, in comparison to what we have seen with the other FAs.

Finally, the generic reading with (in)frequent, sporadic, periodic, daily, and other fixed-frequency FAs is systematically available only with event nouns (e.g. 17a) and is more restricted with sortal nouns. When it does arise with the latter, an event description has to be recovered from the modified nominal, as seen in the paraphrases in $27 .{ }^{17}$

(27) a. A frequent cup of coffee helps keep John awake.

= Drinking a cup of coffee frequently helps keep John awake.

b. Occasional newspaper articles are part of John's job.

$=$ (e.g.) Writing/Editing newspaper articles occasionally is part of John's job.

Such examples indicate that these FAs combine with sortal nouns only when they can be coerced to event descriptions, following Schäfer 2007, and we will see in the following section that a similar restriction to event nominals is also found with these FAs under the adverbial reading. This forced coercion may explain why we generally fail to find examples of these FAs in generic definite singulars, given that event nominals (and, by extension, coerced event descriptions) ostensibly do not meet the 'well-establishedness' condition on the use of the definite article with kind descriptions in English. If such a well-established kind could be found, we would expect the definite article to be acceptable. One such example might be 28 .

(28) The daily rush hour talk show has become a staple of radio programming.

In the following, we will see that the adverbial reading — when available — displays essentially the same determiner restrictions as we have observed here. One of our goals is to explain this fact.

\footnotetext{
${ }^{17}$ An anonymous referee observes that this sort of reading is not easily available with bare mass sortal nouns.
}

(i) ??Occasional coffee helps keep John awake.

We suspect that this restriction is related to a similar restriction on the use of bare sortal nominals with the putative adverbial reading of FAs analyzed in Gehrke \& McNally 2014. We refer the reader to that work for further discussion; see also brief comments in $\mathrm{n}$. 24, below. 
The ADVERBIAL READING. On the adverbial reading, first observed in Bolinger 1967 and the most discussed of the three putative interpretations for FAs, the adjective seems to scope outside of the nominal it occurs in, in fact over the entire sentence, as illustrated in 29 (repeated from 4a) and its paraphrase.

(29) The occasional sailor strolled by.

= Occasionally, a sailor strolled by.

This apparent wide scope is not possible for the FA on either the internal or generic reading, as illustrated in 30 .

(30) a. A frequent sailor won the regatta.

$\neq$ Frequently, a sailor won the regatta.

b. A frequent check-up is essential. $\neq$ Frequently, a check-up is essential.

Stump (1981), Zimmermann (2003), and Schäfer (2007) have all observed that this reading is possible only with the (in)definite articles and semantically bleached possessives, as illustrated in 31 .

(31) We saw an/the/your occasional car on the road.

$=$ Occasionally, we saw a car on the road.

In contrast, if the examples with other determiners in 32 are acceptable at all, they cannot be paraphrased by an adverbially used FA but rather exemplify the internal reading (which is odd for sortal nouns like car).

(32) a. ??We saw each occasional car on the road.

$\neq$ Occasionally, we saw each car on the road.

b. ??We saw two/some/many occasional cars on the road. $\neq$ Occasionally, we saw two/some/many cars on the road.

As with the generic reading, however, there are more restrictions on the adverbial reading than the previous literature has assumed. In particular, if we take as our departure point the example in $4 \mathrm{a}$ and start substituting in different FAs and determiners, we see that this reading is not systematically possible for all determiner-FA combinations. It is clearly available with occasional with both the definite and indefinite articles (33).

(33) a. The occasional sailor strolled by. = Occasionally, a sailor strolled by.

b. An occasional sailor strolled by. = Occasionally, a sailor strolled by.

Note that the paraphrase in these cases always involves the indefinite article on the noun phrase that is modified by the FA in the paraphrased example. In contrast, the adverbial reading is possible with odd and with rare only with the definite article (34 and 35; '??' indicates the unavailability of the relevant reading).

(34) a. The/??An odd sailor strolled by. = On odd occasions, a sailor strolled by.

b. He might point out the[/??an] odd bird or tell us the name of a plant, but these park excursions were not botanical treks.

(COCA)

$=$ On odd occasions, he might point out a bird ...

c. ... Brown himself did imbibe the[/??an] odd drink (he appears not to have been a temperance advocate) ...

(COCA)

= On odd occasions, Brown himself did imbibe a drink ...

(35) a. The pier is still used by the[/??a] rare passenger. (Google books)

$=$ Rarely, the pier is still used by a passenger. 
b. she runs her family's Sea-Vue Motel and Restaurant on a patch of northern Florida coastline ... that sees only the[/??a] rare tourist.

(COCA) $=\ldots$ that rarely sees a tourist

c. In Hinsonville, the[/??a] rare family had just one parent, and that condition was usually quickly altered by the second marriage of the widow or widower.

(Google books) = Rarely, a family had just one parent.

Thus, with these three FAs we observe the same determiner restrictions that we found with the generic reading.

Moreover, in combination with sortal nouns we cannot substitute in any other FAs with either the definite or indefinite determiner and preserve the adverbial reading $(36 a, b, 37)$. In the case of the FA frequent, which has been claimed to be sensitive to plurality, even placing the noun in the plural does not help (36c).

(36) a. An (in)frequent/sporadic/periodic sailor strolled by. $\neq$ (In)frequently/Sporadically/Periodically, a sailor strolled by.

b. The (in)frequent/sporadic/periodic sailor strolled by. $\neq(\mathrm{In})$ frequently/Sporadically/Periodically, a sailor strolled by.

c. Frequent sailors strolled by. $\neq$ Frequently, a sailor/sailors strolled by.

(37) a. A daily/weekly/monthly sailor strolled by. $\neq$ Daily/Weekly/Monthly, a sailor strolled by.

b. The daily/weekly/monthly sailor strolled by. $\neq$ Daily/Weekly/Monthly, a sailor strolled by.

There has already been some debate in the literature as to whether frequent specifically allows the adverbial reading at all. Zimmermann (2003; following Larson 1998) claims, contra Stump 1981 (see also Moltmann 1997, Schäfer 2007, Gehrke \& McNally 2011), that the adverbial reading is only possible with FAs of relative Infrequency (cf. n. 6). The examples in 36 indicate that the crucial fact is not the (in)frequency entailments of the FA. When one looks at the sort of examples that have been used to support the existence of the adverbial reading for the FAs in 36 and 37, what one discovers is that the FA consistently modifies an event noun (for example, the following, from Stump 1981). ${ }^{18}$

\footnotetext{
${ }^{18}$ There appear to be a few counterexamples to this generalization. First, Bolinger (1967) offers the example an infrequent visitor was seen (see also Zimmermann's (2003) variant the infrequent visitor was seen). We have already seen exceptional behavior for stage nouns like visitor in combination with rare. We suspect that the adverbial paraphrase with these is an artifact of the event- or time-dependent criterion of identity associated with these nouns (in contrast to what Barker 1999 refers to as the criterion of long-term self-identity, ostensibly characteristic of other participant nouns such as sailor). However, since the analysis of stage nouns would introduce additional complexities to the already complex set of facts that we discuss, we do not consider them further here.

Second, Stump (1981) provides the example John got his message across to an infrequent student, but such successes were few and far between (his ex. 4). In this case, we simply do not share the judgment that this example has an adverbial paraphrase, and we have not found examples like it in our corpus searches. Schäfer (2007) claims that the adverbial reading is possible with adjectives of relative infrequency with any sort of noun - in contrast to adjectives of relative frequency, which, he claims, as does Zimmermann (2003) and as we do here, allow the reading only with event nouns - but his examples all involve occasional, which, as we have already seen (and as we discuss below), is special.

Finally, Gehrke \& McNally 2011 cites examples like those in (i). It is observed that these are restricted to certain senses of certain verbs with certain sorts of arguments (contrast (ii)).
}

(i) a. She wrote frequent letters. = Frequently, she wrote letters.

b. She baked frequent batches of cookies. = Frequently, she baked batches of cookies. 
(38) a. The storm was punctuated by a sporadic crash of thunder.

b. Mary paid her friend a frequent visit.

c. A yearly eclipse left the city in total darkness.

These facts lead us to two conclusions. First, whatever specific combination of lexical and compositional factors yields the adverbial paraphrase in examples like 33-35 is much less extended than has been taken for granted in the literature: it is specific to $o c$ casional, odd, and rare. The fact that an adverbial paraphrase is available with other FAs such as frequent should not mislead us; it arises under completely distinct conditions, namely, only when the FA modifies an event noun, indicating a distinct origin for the paraphrase. Second, the choice of the definite vs. indefinite article, which has not previously received serious attention in the literature on FAs, in fact has a crucial role to play in the interpretation of the nominal containing the FA, and the pattern of data suggests that it is the same role for both the adverbial and the generic readings.

Summarizing, our review of the data has uncovered several observations that have been missed or underappreciated in previous literature, all of which point to a distinguished behavior for occasional vs. odd and rare vs. the other FAs. These lead us to the lexically grounded perspective on FAs to which we now turn.

2.2. Changing the Perspective: temporal vs. NONTEMPORAL Distribution. In this section, we bring the generalizations from the previous section together with some additional data, first from English and then from German, to support the claim that there is a fundamental bifurcation in FAs involving temporal vs. nontemporal distribution. This bifurcation is grounded in the observed contrast in 5-7 vs. 8, illustrated again in 39 .

(39) a. a glimpse of commerce - the occasional/odd/rare office, barbershop, or Vietnamese strip mall ...

b. ??a glimpse of commerce-the weekly/frequent/infrequent/periodic/ sporadic office, barbershop, or Vietnamese strip mall ...

The reader can no doubt already anticipate that we place frequent, infrequent, periodic, sporadic, and the fixed-frequency FAs (daily, etc.) in the temporal distribution category, and odd and rare in the nontemporal category. We argue that occasional effects both sorts of distribution, as summarized in Table 1.

TYPE OF FA

Nontemporal distribution

Adverbial reading with nonevent nouns

Internal reading

Predicative use on relevant reading

Determiner used with the generic and/or adverbial reading

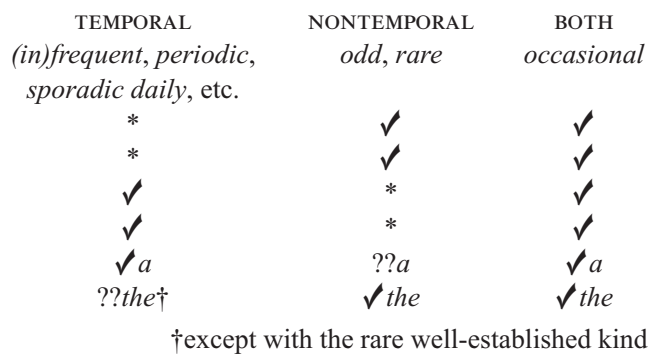

TABLE 1. Empirical generalizations revised.

(ii) a. ??She read frequent letters to her mother.

b. ??She sold frequent batches of cookies.

c. ??She baked frequent cookies.

See Gehrke \& McNally 2014 for arguments that, despite appearances, the FAs are actually predicated of eventualities in these examples, just as in 38 . 
We have already seen that the FAs we put in the temporal-distribution class systematically allow an adverbial interpretation only with event nouns, systematically license the internal reading (with participant nouns), and are rarely, if ever, found with the definite article on the generic reading. Those that allow for nontemporal distribution, by contrast, systematically allow an adverbial interpretation with all kinds of nouns, do not license the internal reading, and require the definite article on the generic as well as the adverbial reading. Table 1 also presents one fact we have not yet discussed, namely, that nontemporal FAs on the relevant interpretation can only be used attributively and not in predicative position; no such restriction holds on temporal FAs. ${ }^{19}$ The single exception to all of these generalizations is occasional, which shows properties of both subgroups across the board. We take this as evidence that occasional is ambiguous and suspect that the failure to appreciate this fact in the past has made it difficult to fully understand the behavior of FAs. In the rest of this section, all generalizations that we make will be understood to extend to occasional under disambiguation.

TEMPORAL VS. NONTEMPORAL DISTRIBUTION IN ENGLISH. Table 1 reveals several correlations that will guide our analysis. The first is that those FAs that are specialized for nontemporal distribution cannot yield the internal reading. This suggests that there must be something crucially temporal about the distribution we find with the internal reading. It is suspicious that the internal reading is also restricted to nouns that can be claimed to have an event argument associated with them. In contrast, the strong correlation between the FAs that license the nontemporal reading and those that systematically license the adverbial reading - even with nouns that do not denote events - indicates that the distribution we find with the adverbial reading is not temporal in nature, nor is it crucially connected to the presence of an event argument.

Second, odd and rare combine only with the definite article, independently of whether the associated paraphrase is generic or adverbial, or whether it is clearly nontemporal vs. not obviously so. This suggests that the semantics of DPs containing these FAs (as well as those containing occasional with the definite article) should be computed in fundamentally the same way no matter whether the resulting sentence is paraphrasable one way or the other. Moreover, we further hypothesize that the distribution effected by FAs is fundamentally the same (i.e. what we have called nontemporal) no matter the context in which the FA appears and even if the paraphrase suggests otherwise.

Third, unlike occasional, odd, and rare, the FAs that lack the nontemporal reading systematically resist the definite article on the generic reading (40).

(40) a. ??the daily office, barbershop, or Vietnamese strip mall ...

b. A/??The daily shower is good for you.

This leads us to hypothesize that there is something different about the generic nominals in which odd, rare, and the relevant uses of occasional appear vs. those in which temporal FAs appear.

A fourth observation, not noted in previous literature or in the discussion up to now, is that the possibility of a predicative use of the FA also correlates with its compatibility with the indefinite article on the generic reading. Specifically, those FAs that allow the indefinite article on the generic reading - that is, those that are strictly temporally dis-

\footnotetext{
${ }^{19}$ Throughout we use (NON)TEMPORAL FA as shorthand for (NON)TEMPORALLY INTERPRETED FA.
} 
tributing - can also be used as predicates with the relevant interpretation (41), whereas nontemporal FAs cannot (42). ${ }^{20}$

(41) a. A(n) weekly/infrequent/frequent/periodic/sporadic check-up is necessary.

b. The check-up was weekly/infrequent/frequent/periodic/sporadic.

(42) a. ??A(n) occasional/odd mosquito is harmless.

b. ??The mosquito was occasional/odd.

In this respect, nontemporal FAs behave like nonintersective adjectives, for example former.

(43) ??The president is former.

What these data show is that different FAs impose different sortal restrictions on the nominals they can be predicated of, and that the FA can appear in an indefinite singular generic nominal just in case it is sortally compatible with the noun it modifies. This, in turn, suggests that in indefinite DPs such as those in 41a, the FA is acting as an intersective modifier. In contrast, this cannot be the case in examples involving the definite article, as in 44.

(44) The occasional/odd/rare mosquito is harmless.

In sum, the data suggest that a fully unified semantics for FAs is not possible, contrary to what Schäfer 2007 and Gehrke \& McNally 2011 maintain, but, in the spirit of what these studies argue, the lines along which the unity breaks down do not correspond to the paraphrases that have been proposed in the literature. Crucially, whether one semantics or another is involved appears to depend on the specific FA at issue, and the distributional data suggest that these semantics cross-cut the internal/generic/adverbial distinction previously made in the literature.

Before we turn to the analysis of these facts, we briefly consider the behavior of FAs in German, which turn out to reinforce the generalizations made above.

A BRIEF COMPARISON WITH GERMAN. ${ }^{21}$ The lexically based division between the temporal and nontemporal FAs that we have identified for English is supported by German data, insofar as German appears to have only temporal FAs. This sort of crosslinguistic variation is what we expect if the FAs fall into lexical subclasses, since lexical inventories vary from language to language, but is unpredicted on an analysis that does not posit different types of FAs. ${ }^{22}$

${ }^{20}$ Note that although rare can be used predicatively, this also appears to be the relational use mentioned in connection to the examples in 15 .

(i) That mosquito was rare (in these parts/ten years ago).

When this use of rare occurs attributively, as in (ii), the sentence is acceptable but lacks the so-called adverbial reading.

(ii) The rare [with respect to some spatial or temporal domain] mosquito is harmless.

We return briefly to this sort of example in $\$ 3.2$.

${ }^{21}$ Abbreviations used in glosses: ACC: accusative, c: complementizer, GEN: genitive, NEG: negation.

22 James McCloskey (p.c.) points out to us that Irish appears to be the mirror image of German, in the sense that it lacks temporal FAs (for meanings like frequent, occasional, etc.) but has one adjective that could count as a nontemporal FA, namely corr. As McCloskey reports, this adjective has the meaning 'peculiar, unusual' in postnominal position, as in (i).

(i) fear corr man peculiar

'a strange/weird man'

He furthermore observes that in prenominal position it is interpreted like a nontemporal FA, and he provides the (naturally occurring) examples (and translations) in (ii). 
Observe that the FA uses of odd and rare translate into German with temporal expressions only, namely gelegentlich 'occasional' and selten, which is cognate with seldom. Moreover, nontemporal interpretations of the kind we observed for English occasional are impossible with gelegentlich.

(45) *Ein gelegentlicher/Der gelegentliche Matrose ist 2 Meter groß. an occasional the occasional sailor is 2 meters tall intended: 'An/The occasional sailor is 2 meters tall.'

The adverbial interpretation of the classical example is unacceptable (46a; see also Schäfer 2007), ${ }^{23}$ whereas an internal reading is possible with participant nouns (46b).

(46) a. *Ein gelegentlicher/Der gelegentliche Matrose schlenderte vorbei. an occasional the occasional sailor strolled by intended: 'An/The occasional sailor strolled by.'

b. Ein gelegentlicher/Der gelegentliche Radfahrer kam vorbei. an occasional the occasional cyclist came by

'Someone/The person who occasionally bikes came by.'

Instead of the classical example in 46a, Zimmermann (2003) uses the example in 47a (his 27a) to exemplify the adverbial reading in German. He furthermore notes that, unlike in English, in German (and in Finnish) [FA N] combinations allow for the adverbial reading only in subject position, and never in object position, as illustrated by the contrast between $47 \mathrm{a}$ and $47 \mathrm{~b}-\mathrm{d}$ (his $27 \mathrm{~b}-\mathrm{d}$ ).

(47) a. Ein gelegentlicher Kunde betrat den Laden. an occasional customer entered the shop

'Occasionally, a customer entered the shop.'

b. \#PAGAD zerstörte das gelegentliche Gebäude. PAGAD destroyed the occasional building

c. \#Peter schickte einer gelegentlichen Frau Blumen. Peter sent an occasional woman flowers

d. \#Wir stoppten bei dem gelegentlichen Rasthaus. we stopped at the occasional roadhouse

Zimmermann attributes this observation to the fact that in German (and in Finnish) nonsubject quantified phrases cannot take inverse scope at LF (logical form) and takes this

(ii) a. Tá corr-chorrán fós féin sa gceantar seo.

is odd-sickle still even in.the area this

'There's still the odd sickle in this area.'

b. an t-ór ar chreid corr-dhuine go raibh sé ann

the gold $\mathrm{C}$ believed odd-person $\mathrm{C}$ was it there

'the gold that the odd person believed was there'

c. Ní bhíodh idir í agus uncail a hathar ach an corr-fhocal.

NEG used.to.be between her and uncle her father.GEN but the odd-word

'There was only the odd word (exchanged) between herself and her father's uncle.'

Given that, in Irish, prenominal adjectives form compounds with the nouns they modify, a complex determiner analysis involving the incorporation of the adjective into the determiner is out of the question. Unlike English nontemporal FAs, however, Irish corr does not require the definite article (cf. (iia,b)), though it is compatible with it (cf. (iic)). According to McCloskey, the presence or absence of the definite article does not have a semantic consequence.

Though further research into these data is needed, if it is correct that Irish is a language that has nontemporal but not temporal FAs, it would further support our division of FAs into these two lexical subclasses.

${ }^{23}$ Note that German Matrose 'sailor', unlike its English counterpart, is not morphologically derived from a verb like 'sail', and thus does not allow the internal reading. 
to support an analysis on which the FA has the semantics of a sort of quantificational determiner. We discuss and reject this analysis of FAs, dubbed the DETERMINER ANALYSIS, in $\S 4.1$ below; for now, we want to call into question the claim that German allows the adverbial reading for FAs even in subject position.

We presented eleven German native speakers with the data in 47. They unanimously rejected examples like 47b-d, as expected. However, four speakers also rejected 47a, and only one of the seven who accepted it clearly allowed for the adverbial reading. The other six who found it grammatical allowed this sentence under the internal reading only, as supported by spontaneous responses such as 'okay under the reading where this is someone who is a customer occasionally', or 'okay in marketing contexts, where customers are divided into regular, occasional, and one-time customers'. Consistent with this judgment, these speakers all accepted the discourse in 48 , which would be impossible under the adverbial reading, while the speaker who got the adverbial reading for $47 \mathrm{a}$ did not.

(48) Ein gelegentlicher Kunde betrat den Laden. Er hatte rote Schuhe an. an occasional customer entered the shop he had red shoes on 'An occasional customer entered the shop. He was wearing red shoes.'

We thus conclude, contra Zimmermann, that the adverbial reading is not reliably available for $47 \mathrm{a}$.

In contrast, German resembles English in that examples like 38, with event nouns, ARE acceptable, as in 49.

(49) a. Die Gruppe hielt eine tägliche/wöchentliche Diskussionsrunde ab. the group held a daily weekly discussion.session off

'The group held a daily/weekly discussion session.'

b. Das Seminar war seltenen/ gelegentlichen/periodischen/

the department was infrequent occasional periodic sporadischen Prüfungen unterworfen.

sporadic reviews under.thrown

'The department underwent infrequent/occasional/periodic/sporadic reviews.'

We observed in $\$ 2.1$ that although examples such those in 38 have been grouped together in the previous literature with examples such as those in 33-35, under the label 'adverbial reading', this has been done strictly on the basis of the fact that the sentences all admit paraphrases involving frequency adverbs with clausal scope. The fact that only the latter, and not the former, sort of examples are possible in German reinforces our claim that the paraphrases are the result of distinct compositional processes.

Though we have to leave the analysis of the German data for a future occasion, the comparison with English clearly indicates that the temporal/nontemporal distinction within FAs is fundamental. We expect that the analysis we propose for temporal FAs in English should extend to German, whereas German simply does not have nontemporal FAs.

We now return to the English data and their analysis.

3. The PROPOSAL. Our analysis here, like that in Gehrke \& McNally 2011, builds on the premise that natural language allows for reference both to TOKEN (ordinary) entities and events, and to KINDS of entities and events. This premise is by now widely accepted in the case of ordinary entities (Carlson 1977 being the classic reference), and though less commonly made in the case of events, it has roots, for example, in situation seman- 
tics (see Barwise \& Perry 1983) and has gained currency in recent years (e.g. Landman \& Morzycki 2003, Ginzburg 2005, Sailer 2010, Gehrke 2012, Arsenijević et al. 2014).

In the case of nominal expressions, we modulate reference to kinds vs. tokens via a 'layered' DP (Zamparelli 1995). Specifically, we take nouns to denote properties of kinds, as shown in the logical representation in $50 \mathrm{a} .{ }^{24}$ These are converted via inflectional morphology, which we introduce in $50 \mathrm{~b}$ via a syntactic Num(ber) projection, into properties of token entities (see e.g. Farkas \& de Swart 2003, McNally \& Boleda 2004, Déprez 2005, Espinal 2010, Mueller-Reichau 2011, and references cited there for related proposals). In this latter representation, $\mathbf{R}$ is Carlson's (1977) realization relation, and we assume here that existential closure binds off the kind variable in the representation of the noun in $50 \mathrm{~b}$, though alternative techniques could be used for assigning a value to this variable. ${ }^{25}$ Thus, the numberless noun car denotes the set of all kinds of cars (station wagons, sedans, etc.), the (phonologically identical) singular NumP car denotes the set of atomic tokens that realize some car kind, and the plural NumP cars denotes the set of token pluralities of some car kind.

(50) a. $\llbracket\left[{ }_{N P}[\mathrm{~N}\right.$ car $\left.]\right] \rrbracket: \lambda x_{k}\left[\operatorname{car}\left(x_{k}\right)\right]$

b. $\llbracket\left[{ }_{\mathrm{NumP}}[\mathrm{NP} \operatorname{car}]\right] \rrbracket: \lambda y \exists x_{k}\left[\mathbf{c a r}\left(x_{k}\right) \wedge \mathbf{R}\left(y, x_{k}\right)\right]$

We treat verbs analogously to nouns: they, too, start out as predicates of (event) kinds or relations between event kinds and (kind or token) individuals (see 51), which can be turned into predicates of event tokens in composition with functional morphology. As it is not essential to our discussion and would take us too far afield, we do not pursue the question of which functional projection might play a role analogous to Number for verbs and under exactly what conditions it might do so, but one suitable candidate would be Asp(ect); see Gehrke 2015 for discussion and a specific proposal.

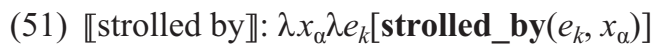

As mentioned in the introduction, we also adopt two important claims from Gehrke $\&$ McNally 2011 . The first of these is that kinds may be realized not only by SINGLE TOKENS but also sometimes crucially by SETS OF TOKENS. The function of the FA is to impose conditions on the distribution of these sets of tokens at a given index. We go beyond Gehrke \& McNally 2011, however, in recognizing that temporal FAs can do this either as modifiers or as predicates, as in 52 (all from GloWbE).

(52) a. When newspapers were king the news cycle was daily.

b. Initially, the payment was monthly.

c. The harvest at the end of the world was reaped by the followers of Horus at the end of the age or cycle of time. It was periodic in the mythology, like the harvests of the earth ...

\footnotetext{
${ }^{24}$ Throughout the rest of the article, we use a subscript $k$ to indicate a variable over kinds, no subscript to indicate a variable over tokens, and a subscript $\alpha$ to indicate a variable that ranges over either kinds or tokens.

${ }^{25}$ We use the sloppy notation 'at $i$ ' for ease of reading. Note that in what follows the variable $e$ sometimes ranges over atomic events and sometimes, as here, over nonatomic events.

Incidentally, the fact that it is possible to pluralize nouns such as kind, variety, or sort, which form DPs that refer much more easily to kinds than to tokens (as shown by the difficulty with which (ia) licenses discourse anaphora to token situations in (ib) vs. kinds of situations in (ic)), raises the question of whether what we are capturing in this appeal to NP and NumP layers needs a slightly different or more general treatment, or whether we simply need to posit that kinds can also be realized by other kinds.
}

(i) a. I like those kinds of situations.

b. ??I saw them (= situations of those kinds) yesterday.

c. They (= those kinds of situations) are interesting.

However, exploration of this issue is beyond the scope of this article. 
d. The illness was sporadic, at first.

e. The local bus ... was infrequent but arrived with uncanny accuracy ...

f. There had been an iciness developing between them. At one time it was occasional, but now it was frequent.

Another detail not observed in Gehrke \& McNally 2011 is that temporal FAs have an additional use as predicates or modifiers of token-plurality descriptions, as in 53a (cp. 53b).

(53) a. Her job changes were frequent.

b. ??Her job change was frequent.

The reason for the plurality requirement in this case will become clear when we introduce the semantics below. In contrast, nontemporal FAs function only as kind-level modifiers describing the distributions of the sets of tokens realizing the kinds in question. As mentioned in $\$ 2.2$, we have not found examples of these FAs as predicates on the relevant interpretation (recall 42 and n. 20).

The second claim we adopt from Gehrke \& McNally 2011 is that the semantics of declarative sentences has to allow the possibility that they can be used to make not just assertions about event tokens (typically represented via existential quantification over an event-token variable), but sometimes also assertions about event kinds. This will be crucial to explaining the adverbial paraphrases of FAs.

We now present the analyses of temporal and nontemporal distribution with FAs in turn.

3.1. Temporal Distribution. We propose that temporal FAs denote simple properties of event kinds or tokens. This can be formalized as in 54 .

(54) $\llbracket \mathrm{FA}_{\text {temp }} \rrbracket: \lambda e_{\alpha}\left[\mathbf{F} \mathbf{A}_{\text {temp }}\left(e_{\alpha}\right)\right]$

The satisfaction conditions for $\mathbf{F A}_{\text {temp }}$ when it applies to kinds and token pluralities of eventualities appear in 55a and 55b, respectively. In plain language, these conditions state that a temporal FA is true of its argument at a (temporal) index $i$ just in case the distribution of the set that realizes the argument (when it is a kind) or the set of atomic parts of that argument (when it is a plurality), at the index in question, is whatever distribution the FA requires (distribution in the representation is a function that yields the distribution dist of a set of entities at the given index, with values like high, low, daily, etc.). ${ }^{26}$

(55) a. $\forall e_{k}, i\left[\mathbf{F} \mathbf{A}_{\text {temp }}\left(e_{k}\right)\right.$ at $i \leftrightarrow \operatorname{distribution}\left(\left\{e: \mathbf{R}\left(e, e_{k}\right)\right.\right.$ at $\left.\left.\left.i\right\}\right)=d i s t\right]$

b. $\forall e, i\left[\mathbf{F} \mathbf{A}_{\text {temp }}(e)\right.$ at $i \leftrightarrow \operatorname{distribution}\left(\left\{e^{\prime}: \operatorname{atomic}-\mathbf{p a r t}-\mathbf{o f}\left(e^{\prime}<e\right)\right.\right.$ at $\left.\left.\left.i\right\}\right)=d i s t\right]$

Intuitively, a distribution is a relation between a (nonsingleton) set of events and a welldefined stretch of time (or, as will be the case with nontemporal FAs, possibly space). A temporal FA can be combined with a numberless nominal describing a kind of event, because from a single event kind a set of token event realizations can be retrieved, whose distribution can then be characterized. Similarly, the FA can be combined with a plural nominal describing a plurality of event tokens, because the atoms of that plurality can be retrieved and be attributed a particular distribution.

\footnotetext{
${ }^{26}$ In addition, the distribution function must guarantee that the members of the set be properly individuable and that the distribution be sufficiently regular; see Stump 1981, Zimmermann 2003, and Schäfer 2007 for discussion, with Schäfer offering perhaps the most sophisticated proposal in this regard. Since the means by which the appropriate distribution is guaranteed is not crucial to our analysis and the existing proposals involve considerable technicalities, we do not discuss the options further here.
} 
In contrast, the FA will never combine with a singular nominal describing a token event because there is no way to give an individual event an interesting distribution over time, hence the unacceptability of 53b. We see a similar effect in cases where the FA is used as a modifier of a singular nominal that is not naturally interpreted as a kind description, as in 56a (contrast 56b).

(56) a. We attended a(n) ??frequent/??infrequent/??sporadic/??periodic/??daily party.

b. We attended frequent/infrequent/sporadic/periodic/daily parties.

To the extent that the examples in 56a are acceptable at all, the FA can only be understood as contributing to a description of a subkind - for example, a kind of party that occurs daily. In order to describe the distribution of token events, the plural must be used, as in $56 \mathrm{~b}$.

The fact that temporal FAs have this dual use, in the sense that they describe either an event kind or event tokens, means that one has to proceed with great care in analyzing the data. For the remainder of this article we are only concerned with application of the FA to kinds, as in 55a. However, we hope that this brief consideration of how temporal FAs can also be predicated of token pluralities of eventualities will prove useful in future work on various complex facts surrounding these expressions that we are not able to address here (see Gehrke \& McNally 2014 for one set of data where the FA actually requires token pluralities).

The semantics in 54 and 55a, and its effect in combination with a noun, is illustrated in 57 for frequent as in a frequent downdraft; we posit that the adjective combines with the noun via a predicate conjunction rule (see e.g. Larson 1998).

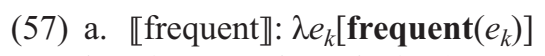

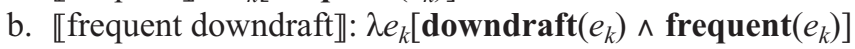
$=\lambda e_{k}\left[\mathbf{d o w n d r a f t}\left(e_{k}\right) \wedge \operatorname{distribution}\left(\left\{e: \mathbf{R}\left(e, e_{k}\right)\right.\right.\right.$ at $\left.\left.\left.i\right\}\right)=h i g h\right]$

The NP frequent downdraft denotes a property of the downdraft event kind whose collective token realizations have a high distribution over the given index $i$. In adding an intersective condition on the kind, the FA effectively creates a subkind, one characterized by the distribution of the instances of the superkind and which can be contrasted with other subkinds characterized by other distributions. This analysis captures the fact that, on a conceptual level, it is clearly meaningful to characterize kinds of eventualities according to their distribution in time, as is particularly clear with fixed-frequency adjectives - for instance, we classify meetings as daily, weekly, monthly, annual, and so forth.

When a kind description containing a temporal FA combines with Number, the result is a description of token individuals of a kind whose distribution is determined by the FA, as in 58, which denotes the set of token broadcasts of the daily kind.

(58) $\llbracket\left[{ }_{\mathrm{NumP}}[\mathrm{NP}\right.$ daily broadcast $\left.]\right] \rrbracket$ : $\lambda e \exists e_{k}\left[\operatorname{broadcast}\left(e_{k}\right) \wedge \operatorname{daily}\left(e_{k}\right) \wedge \mathbf{R}\left(e, e_{k}\right)\right]$

This sort of use treats the FA as creating a meaningful subkind (for instance, we subclassify broadcasts according to their periodicity - daily, weekly, etc.). Alternatively, the FA can modify a nominal that has already been converted into a description of a plurality of tokens (i.e. at the level of NumP), as in 59, which denotes the set of token pluralities of downdrafts whose atoms form a set with a high distribution at some temporal index.

(59) $\llbracket[$ NumP frequent $[$ NumP downdrafts $]] \rrbracket$ : $\lambda e \exists e_{k}\left[\operatorname{downdrafts}\left(e_{k}\right) \wedge \mathbf{R}\left(e, e_{k}\right) \wedge\right.$ frequent $\left.(e)\right]$

The difference in the entailments of these different sorts of representations will become evident immediately below. 
SOME BASIC FACTS ACCOUNTED FOR. The intersectivity of the semantics for temporal FAs distinguishes our analysis from those in previous works and accounts for a couple of facts about which other analyses have had nothing to say, a point that we further elaborate on in $\$ 4.2$. First, the intersective semantics sheds light on the fact that temporal FAs occupy postnominal position in Romance languages (e.g. Spanish), a position reserved for intersectively interpreted modifiers, as shown in $60 .^{27}$

(60) un problema frecuente

a problem frequent

'a frequent problem'

(Spanish)

Second, this semantics predicts that temporally interpreted FAs will combine with other intersective modifiers of the same general sort (for example, additional descriptors of the kind of event in question), in the way that intersective modifiers generally do. On the one hand, they should be able to coordinate with such modifiers, a prediction borne out by examples such as $61 \mathrm{a}, \mathrm{c}$; and, on the other, there should be a certain freedom in the ordering of these modifiers, as in $61 \mathrm{~b}, \mathrm{~d} .{ }^{28}$

(61) a. ... an occasional and brief downdraft will occur within the chimney ... ${ }^{29}$

b. a brief, occasional downdraft $=$ an occasional, brief downdraft

c. a frequent and widely recognized problem

d. a frequent, widely recognized problem $=$ a widely recognized, frequent problem

The fact that the output of modification by the FA can serve as the input to additional modification demonstrates that the set of kinds denoted by the [FA N] need not be a singleton set. That is, for example, occasional downdraft denotes a set of kinds of downdrafts whose extension might include brief downdrafts, cold downdrafts, and so forth. This predicts the existence of examples such as the following, where the bare plural containing the FA denotes a set of kinds of abnormalities with a low distribution.

(62) A number of occasional abnormalities have been described, including cardiac defects, cleft lip/palate, scoliosis, genitourinary anomalies, and central nervous system anomalies.

The analysis also predicts that nominals containing temporal FAs should in principle be able to be headed by a variety of determiners, as in the examples from (i) in n. 16, repeated in 63 .

(63) a. No daily news program can match this one.

b. John agreed to conduct one weekly inspection a year.

\footnotetext{
${ }^{27}$ Intersectively interpreted adjectives can also sometimes appear in prenominal position in Spanish, but in such cases they are generally understood nonrestrictively, and thus rarely occur in this position without a definite or demonstrative determiner. See, for example, Demonte 2008 for discussion and further references.

${ }^{28}$ This combinatorial freedom is somewhat restricted. The greater the semantic difference between the information provided by the two modifiers, the more difficult it is to combine them absolutely freely, as illustrated in (i).
}

(i) a. ?a yearly and external review

b. a yearly external review = an external yearly review

c. ?a frequent and international problem

d. a frequent international problem vs. ??an international frequent problem

However, we suspect that pragmatic factors intervene in accounting for these restrictions, since similar effects are found on adjective coordination and ordering more generally (see e.g. Bouchard 2005, Svenonius 2008, Cinque 2010, and references cited there for discussion of adjective ordering).

(ii) a. ?a tall and fascinating child

b. a tall, fascinating child vs. ?a fascinating, tall child

${ }^{29} \mathrm{http}: / /$ www.patentstorm.us/patents/6298844/description.html 
Note that these sentences are not generic, and thus would not be expected to conform to the determiner restrictions typically associated with generic sentences, including those that motivated the postulation of the so-called generic reading discussed above. However, we can now understand why Stump (1981) would have considered the nominals in these sentences also to exemplify the generic reading of the FA. On our analysis, the generic flavor one might attribute to no daily news program comes from the fact that it can be interpreted as a quantifier over KINDS of news programs that occur on a daily basis, for example, one featuring on-site reports or one based on interviews with specialists (see also Schäfer 2007 for comments in a similar spirit). Alternatively, via the sort of semantics illustrated in 58, the DP can be interpreted as a quantifier over token news programs that instantiate the daily news kind (for example, Morning Edition or The CBS Evening News). A similar ambiguity can be attributed to one weekly inspection.

CAPTURING THE DIFFERENT PARAPHRASES. We now illustrate how the semantics in 54 can be used to generate the three readings that were introduced in $\S 2.1$. We use frequent for illustration, whose denotation and relevant satisfaction conditions are given in 64 .

(64) a. $\llbracket$ frequent $\rrbracket: \lambda e_{\alpha}\left[\right.$ frequent $\left.\left(e_{\alpha}\right)\right]$

b. $\forall e_{k}, i\left[\right.$ frequent $\left(e_{k}\right)$ at $i \leftrightarrow \operatorname{distribution}\left(\left\{e: \mathbf{R}\left(e, e_{k}\right)\right.\right.$ at $\left.\left.\left.i\right\}\right)=h i g h\right]$

Recall the internal reading with this temporal FA, illustrated in 65.

(65) John is a frequent sailor.

This reading comes about when the FA modifies a deverbal participant noun or a stage noun such as passenger. We hypothesize, building on the proposal in Winter \& Zwarts 2012 , that what distinguishes these nouns from other nouns is the presence in their semantic representation of an additional event argument (or more specifically, as we assume here, an event kind argument), along with a relation that specifies the role the participant described by the noun plays in that kind of event, here Agent. Thus, given our assumptions about the layered DP, the representation of a noun like sailor will be as in 66a, which will be converted into a property of token individuals via the introduction of number morphology, as in $66 \mathrm{~b}$ (note that the existential closure introduced when Number is added will bind off the event-kind variable in the noun's representation, in addition to the other kind variable). This representation guarantees that $x$ bears the appropriate role in the particular event.

(66) a. $\llbracket\left[{ }_{\mathrm{NP}}[\mathrm{N}\right.$ sailor $\left.]\right] \rrbracket: \lambda x_{k} \lambda e_{k}\left[\operatorname{sail}\left(e_{k}\right) \wedge \operatorname{Agent}\left(x_{k}, e_{k}\right)\right]$

b. $\llbracket\left[\right.$ NumP $\left[\mathrm{NP}\right.$ sailor]]]: $\lambda y \exists x_{k}, e_{k}\left[\operatorname{sail}\left(e_{k}\right) \wedge \operatorname{Agent}\left(x_{k}, e_{k}\right) \wedge \mathbf{R}\left(y, x_{k}\right)\right]$

The FA will thus combine with the noun before the latter combines with Number, as in 67 , much in the way that relational adjectives combine with kind descriptions before these are turned into token-level descriptions on the analysis in McNally \& Boleda 2004.

(67) $\llbracket[\mathrm{NP}$ frequent sailor $] \rrbracket: \lambda x_{k} \lambda e_{k}\left[\operatorname{sail}\left(e_{k}\right) \wedge \operatorname{Agent}\left(x_{k}, e_{k}\right) \wedge \operatorname{frequent}\left(e_{k}\right)\right]$

Since the FA is sortally restricted to apply to events, the only option is for it to apply to the event argument in the noun's representation. The exact mechanism via which the adjective accesses this argument is not crucial; see, for example, Pustejovsky 1995, Larson 1998, and McNally \& Boleda 2004 for different implementations.

When Number is added, the result is a description of those token individuals of the sailor kind who participate in the kind of event that can be described as frequent sailing.

(68) $\llbracket[$ NumP frequent sailor $] \rrbracket$ :

$$
\lambda y \exists x_{k}, e_{k}\left[\operatorname{sail}\left(e_{k}\right) \wedge \operatorname{Agent}\left(x_{k}, e_{k}\right) \wedge \operatorname{frequent}\left(e_{k}\right) \wedge \mathbf{R}\left(y, x_{k}\right)\right]
$$


Note that expressions with representations like that in 68 should be able to combine with any determiner, and indeed we saw in $\$ 2.1$ that this is possible.

An additional prediction of this analysis is that any token-level modification should have to appear farther away from the head noun than the FA does, since it will only be able to be added once a variable corresponding to the token individual is introduced by Number (see McNally \& Boleda 2004 for related examples). This prediction is also borne out: $69 \mathrm{~b}$ entails that skilled sailors are a recognizable subkind of sailor, rather than simply entailing that Martin is skilled.

(69) a. Martin is a skilled frequent sailor.

b. ??Martin is a frequent skilled sailor.

Next we consider the generic reading, which comes about when the FA-modified noun appears with a generic predicate. There are two kinds of cases: those in which the modified noun describes an event (70), and those in which it does not (71), at least not at first sight. Recall that in both cases, as a rule, the generic reading requires the indefinite article or bare plural and is incompatible with the definite article.

(70) a. A periodic inspection is important.

b. Periodic inspections are important.

c. ??The periodic inspection is important.

(71) a. A frequent glass of wine is healthy.

b. Frequent glasses of wine are healthy.

c. ??The frequent glass of wine is healthy.

Recall as well that the facts in 70c and 71c correlate with the fact that, without the FA, the definite also lacks a generic reading, as illustrated in 72 .

(72) a. The inspection is important.

b. The glass of wine is healthy.

Since the FAs in 70 and 71 simply contribute an additional intersective condition on the nominal description, their presence or absence should have no impact on the eventual availability of a generic or nongeneric interpretation for the nominal. Whatever readings the nominal independently allows with whatever combination of articles should be just those that are available when the FA is present. We assume that this same explanation will extend to the failure of the definite article to appear with temporal FAs on the so-called adverbial reading, discussed below, which, on our analysis, also crucially involves interpreting the FA-modified DP as a kind description.

If, for independent reasons, the nominals in 72 must be interpreted as referring to familiar token (single) individuals, we can also now explain why 70c and 71c not only lack a generic reading, but are in fact also odd: we have already shown with examples such as 53b and 56a that, when used as a descriptor of tokens, temporal FAs require their argument to denote a plurality. ${ }^{30}$

Now let us sketch a semantics for these examples. The acceptable sentences in 70 are straightforwardly analyzable in the same way as other generic sentences involving indefinite singular and bare plural DPs; we exemplify just the indefinite singular. The question of how best to analyze generic indefinites and bare plurals has been a matter of considerable debate in the literature (see e.g. Carlson \& Pelletier 1995, Mari et al. 2013 for overviews). For the sake of illustration, we assume that the source of genericity in

\footnotetext{
${ }^{30}$ Periodic here marginally allows an interpretation where what is referred to is a familiar token inspection of a periodic kind. This reading can be accounted for with an analysis like that in 58 . Why this option is available in some cases and not others seems to be a matter of pragmatics.
} 
indefinite generic sentences is external to the subject DP and treat the indefinite as nonquantificational (see Farkas \& Sugioka 1983, Cohen 2001, Greenberg 2002, Krifka 2013 , inter alia, for different proposals). Given these assumptions, the representation of $70 \mathrm{a}$ will be as in 73, where Gen represents a generic quantifier.

(73) $\left(\operatorname{Gen} e_{k}: \operatorname{inspection}\left(e_{k}\right) \wedge \operatorname{periodic}\left(e_{k}\right)\right)\left[\operatorname{important}\left(e_{k}\right)\right]$

In prose, 73 says that if $e_{k}$ is an inspection kind of event whose instances are sets with periodic distributions, $e_{k}$ is important. This is the interpretation we want.

For completeness, now consider the representation of a sentence in which the generic operator combines with a NumP containing an FA, as if the example in 70a were analyzed as in 58 .

\section{(74) $\left(\boldsymbol{G e n} e: \exists e_{k}\left[\operatorname{inspection}\left(e_{k}\right) \wedge \operatorname{periodic}\left(e_{k}\right) \wedge \mathbf{R}\left(e, e_{k}\right)\right]\right)[\operatorname{important}(e)]$}

The representation in 74 does not have exactly the same satisfaction conditions as 73 : it is true if, in general, a token inspection that qualifies as being of the periodic inspection kind is important.

When the head noun does not describe an event, as in 71 , coercion of the denotation to an event description is needed. Recall from the discussion of 27 that examples in which temporal FAs modify sortal nouns are systematically equivalent to event descriptions in which an individual of the sort described by the noun is a participant (e.g. 75a is paraphrasable as in $75 \mathrm{~b}) .{ }^{31}$

(75) a. A daily beer is healthy.

b. V-ing a beer on a daily basis is healthy.

This sort of coercion is well known (consider cases such as the interpretation of the book in enjoy the book), and our analysis is compatible with any independently motivated account of coercion (see e.g. Asher 2011 for a recent proposal). Here we simply use a function $\mathbf{E}$ to induce the appropriate coercion (following the notation in Schäfer 2007), yielding the semantic representation for $75 \mathrm{a}$ in 76.

(76) $\left(\operatorname{Gen} e_{k}: \mathbf{E}(\mathbf{b e e r})\left(e_{k}\right) \wedge\right.$ daily $\left.\left(e_{k}\right)\right)\left[\right.$ healthy $\left.\left(e_{k}\right)\right]$

The representation in 76 is fully analogous to 73.

Finally, we turn to the adverbial reading with temporal FAs, that is, the paraphrasability of such FAs in terms of a sentence-level adverb. Recall that with temporal

${ }^{31}$ Stump (1981) cites one sort of example that might appear to counterexemplify this claim: (ia) is not paraphrasable as in (ib).

(i) a. An occasional cup of coffee tastes good when it's cold out.

b. V-ing an occasional cup of coffee tastes good when it's cold out.

However, taste does admit eventuality-describing arguments when they are presented in infinitive form, particularly if they are extraposed, as the following example shows.

(ii) Yes, I use Silk 'soymilk' in my coffee, oatmeal, \& smoothies. It tastes good to drink as well, although I seldom do that.

https://groups.yahoo.com/neo/groups/Peripheral_Neuropathy/conversations/topics/11982?var $=1 \& p=2$

We also observe that the equivalent sentence is acceptable in German (iii), despite the fact that we have shown in $\$ 2.2$ that gelegentlich sortally selects for an event (in contrast to English occasional).

(iii) Ein gelegentliches Bier schmeckt gut.

an occasional beer tastes good

'If one occasionally drinks a beer, it tastes good.'

We therefore conclude that, despite initial appearances, sentences like those in (ia) do not call into question the generalization that generic uses of temporal FAs with sortal nouns systematically involve coercion. 
FAs, this paraphrasability is systematically possible only with event nominals, as illustrated in 77 .

(77) The department has undergone a periodic review (over the last ten years). $=$ Periodically, the department has undergone a review.

Since such sentences are not, as a rule, generic, there is no motivation for using a generic adverbial quantifier to bind the variable in the DP's denotation. We conclude that the DP is an instance of an indefinite-kind nominal of the sort found in sentences like 78 (see e.g. Dayal 2004 and Mueller-Reichau 2011 for additional discussion and examples of indefinite-kind nominals).

(78) a. A giant tortoise has recently become extinct.

b. Fred invented a pumpkin crusher.

The denotation of the nominal in 77 will be composed in exactly the same way as before (see 79a). When the indefinite article is added, the result is $79 b$, where for the sake of illustration we treat the resulting DP as denoting the entity returned by a choice function $f_{i}$ on the set denoted by periodic review (Reinhart 1997, Kratzer 1998). ${ }^{32}$

(79) a. $\llbracket$ periodic review $\rrbracket: \lambda e_{k}\left[\operatorname{review}\left(e_{k}\right) \wedge \operatorname{periodic}\left(e_{k}\right)\right]$

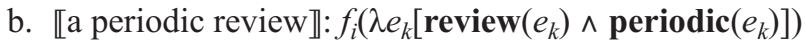

Gehrke \& McNally 2011 observes that, because of the distribution condition on the set of tokens that realize this kind, it is difficult to imagine how any such set could participate in one token event of the sort described by the verb. However, nothing would prohibit it from participating in the KIND of event described by the verb, if the latter could be instantiated by multiple tokens. This observation led to the proposal that sentences with the adverbial reading correspond to propositions about event kinds. Thus, the denotation of 77 is represented as in 80 , where $\mathbf{d}$ stands for the department.

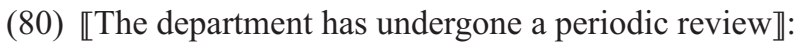

$$
\exists e_{k}\left[\operatorname{undergo}\left(e_{k}, \mathbf{d}, f_{i}\left(\lambda e_{k}^{\prime}\left[\operatorname{review}\left(e_{k}^{\prime}\right) \wedge \operatorname{periodic}\left(e_{k}\right)\right]\right)\right)\right]
$$

Gehrke \& McNally 2011 proposes the following satisfaction conditions for sentences that are used to make assertions about event kinds. First, in order for an event kind to exist at some index $i$, at least one realization of the event kind should exist at $i$. This intuition is formalized as in 81 .

$$
\text { (81) } \forall e_{k}, x_{\alpha}, P, i\left[P\left(e_{k}, x\right) \text { at } i \leftrightarrow \exists e, x_{\alpha}\left[\mathbf{R}\left(e, e_{k}\right) \wedge P\left(e, x_{\alpha}\right) \text { at } i\right]\right]
$$

This is the intuition behind the semantics of existential sentences in McNally 1992 (see also remarks in Strawson 1959); a deeply similar idea underlies Carlson's 1977 analysis of nongeneric sentences involving kind terms. The formalization in 81 entails that if it is true, for example, that a kind event we can describe as undergoing a review has taken place, then a token undergoing of a review must have taken place. Crucially, an analogous condition holds in the vast majority of cases on statements about kind-level participants in token events. If it is true, for example, that the department has undergone a kind of review, it must be true that it has undergone a realization of that kind of review.

Now we can consider what must be the case for a kind of event to exist that involves a kind-level participant realized not by a single token but rather by a set of tokens in a par-

\footnotetext{
${ }^{32}$ Whether the choice-function variable is treated as existentially quantified or as a contextually valued free variable is not crucial here; we treat it as a free variable. Other analyses of the indefinite article would be compatible with our treatment of the FA.

Note that the DP containing the FA can also be understood as denoting a token review of the periodic kind. If the DP were to be interpreted this way in 77 , the sentence would entail only that the department had undergone one token review, rather than a set of reviews.
} 
ticular distribution, as in 80 . Gehrke \& McNally 2011 proposes that each element of the set that realizes the participant should participate in a token event of the relevant event kind. In such cases, it will follow automatically that the corresponding token events will satisfy the same distribution as the token participants. Thus, for 80 to be true, there will have to be a set of token-review-undergoing events with a distribution that can be described as 'periodic'. This is precisely what the adverbial paraphrase expresses.

Note that temporally interpreted FAs will not, as a rule, have an adverbial paraphrase in combination with sortal nouns for a very simple reason: the noun does not describe the sort of entity that the FA can modify. The exception will be cases where the sortal noun's denotation can be coerced to that of an event description. In such cases, we expect that temporally interpreted FAs should be possible with sortal nouns, and indeed that does appear to be the case, as shown in 82 .

(82) We enjoyed a daily/frequent beer with our friends.

$=$ Daily/Frequently, we enjoyed (having) a beer with our friends.

Summarizing, with a single denotation for the temporally interpreted FAs, we have accounted for the three classic readings associated with these adjectives. We now do the same for FAs expressing nontemporal distribution.

3.2. NONTEMPORAL DISTRIBUTION. The semantics for nontemporally interpreted FAs is identical to the one we proposed for temporal FAs except for two important details. First, these FAs are not sortally restricted to describing event distributions; as a result, we find them with all kinds of nouns. Second, and perhaps more interestingly, their semantics is exclusively that of a modifier (see 83) - recall that these FAs lack a predicative use. For now we posit that it serves only as a modifier of predicates of kinds, as opposed to predicates of pluralities of tokens.

(83) $\llbracket \mathrm{FA}_{\text {nontemp }} \rrbracket: \lambda P \lambda x_{k}\left[(\mathbf{F A}(P))\left(x_{k}\right)\right]$

Despite these differences, the satisfaction conditions for nontemporal FAs are the same as those for temporal FAs (compare 84 with 55a).

(84) $\forall P, x_{k}, i\left[\left(\mathbf{F A}_{\text {nontemp }}(P)\right)\left(x_{k}\right)\right.$ at $i \leftrightarrow$

$\left[P\left(x_{k}\right) \wedge\right.$ distribution $\left(\left\{y: \mathbf{R}\left(y, x_{k}\right)\right.\right.$ at $\left.\left.\left.\left.i\right\}\right)=\operatorname{dist}\right]\right]$

We exemplify this semantics in 85 using odd car, where $85 \mathrm{c}$ spells out the satisfaction conditions for $85 \mathrm{~b}$.

(85) a. $\llbracket \operatorname{odd} \rrbracket: \lambda P \lambda x_{k}\left[(\operatorname{odd}(P))\left(x_{k}\right)\right]$

b. 【odd car $\rrbracket: \lambda x_{k}\left[(\operatorname{odd}(\mathbf{c a r}))\left(x_{k}\right)\right]$

c. $\forall x_{k}, i\left[(\operatorname{odd}(\operatorname{car}))\left(x_{k}\right)\right.$ at $i \leftrightarrow\left[\operatorname{car}\left(x_{k}\right) \wedge\right.$ distribution $\left(\left\{y: \mathbf{R}\left(y, x_{k}\right)\right.\right.$ at $\left.\left.i\right\}\right)=$ low]]

Unlike nominals modified by temporal FAs, those modified by nontemporal FAs do not appear to feed descriptions of token individuals. For example, it is not possible to add a descriptive adjective to a nominal modified by a nontemporal FA, in contrast to what we find with temporal FAs (contrast 86a,b).

(86) a. ??There was the intelligent occasional/odd/rare preschooler who could do fractions.

b. There was an interesting daily broadcast on TV.

Intuitively, this is related to the fact that nontemporal FAs do not create meaningful subkinds (as e.g. daily can for broadcasts) that can be converted to descriptions of tokens individuals. Rather, these FAs have a different function entirely, namely (and exclusively) to provide information about the distribution of the realizations of the kind they modify, a point to which we return shortly. 
SOME BASIC FACTS ACCOUNTED FOR. The proposal that nontemporal FAs do not denote simple (first-order) properties of (kinds of) individuals is crucial to account for various contrasts between them and temporal FAs. First, unlike the latter, nontemporal FAs do not coordinate with modifiers that can be given an intersective analysis.

(87) a. ??The museum had the odd/rare and brief visit from school groups.

b. ??The occasional and fast car drove by.

Second, changing the order of these FAs with respect to other modifiers clearly produces a corresponding change in interpretation (to the extent that it is even grammatical), something typical of predicate modifiers but not, as shown above, of modifiers that can be given an intersective semantics.

(88) Only the odd/rare/occasional two-door car will have enough leg room in the back seat.

$\neq$ ?? Only the two-door odd/rare/occasional car will have enough leg room in the back seat.

Third, if nontemporal FAs have a slightly different semantics, and in particular a different semantic type, from temporal ones, we should not be surprised that the two types of FAs have different distributions in different languages. For example, as shown in $\S 2.2$, German lacks nontemporal FAs (or if it has them, we have not identified them yet), and this also appears to be the case for the Romance languages, as illustrated with the following examples from Spanish.

(89) ??Pasaba el \{ocasional coche/coche ocasional\}. passed the occasional car car occasional intended: 'The occasional car passed by.'

Finally, the particular predicate-modifier semantics we have given leads to an account of the determiner restriction on nominals containing nontemporal FAs. The explanation is as follows. In principle, the nominal that the FA combines with denotes a set: the set of kinds described by that nominal. This set will include the general kind associated with the nominal, plus, as noted in the previous section, any recognizable subkinds; for example, car will denote the set that includes the kind described by car, but also the subkinds described by station wagon, sports car, sedan, and so forth (cf. Carlson 1977). In general, we can restrict such kind descriptions (and thus reduce the set of subkinds described) by adding subkind-creating modification (e.g. two-door).

However, whenever we convert the kind description to a description of tokens (on our approach, by adding Number), there is always only one unique kind that the tokens are entailed to be realizing, namely the maximally general kind described by the nominal. For example, the (nongeneric) nominal cars denotes the set of token individuals that are of the car kind. It may be that all of these cars belong to one particular subkind of car (e.g. sedans), but this is not ENTAILED. Though we cannot provide a deep answer as to why this restriction on the unique maximal kind arises, it is an obvious consequence of having to choose some kind for the tokens to stand in the realization relation to, and natural language does not seem to be able to express at once, with a single, noncoordinated nominal, realization relations to multiple kinds. ${ }^{33}$

Although the effect of adding a (nontemporal) FA is not to convert a kind-level description to a token-level description, its effect is similar insofar as it takes a kind description and imposes conditions on the realizations of the corresponding kind. But in

\footnotetext{
${ }^{33}$ Of course, if some token realizes a given kind, it will realize all superkinds of that kind by entailment, but this is not relevant to our point.
} 
order for those conditions to be met, the identity of the kind that will participate in the realization relation must be established, and following the same logic sketched immediately above, we expect it to be the unique, most general kind described by the nominal that the FA combines with. As a result, when the FA combines with a kind description, it returns the description of the unique kind upon whose realizations distributional conditions are being imposed. Thus, nominals containing these FAs should reject any determiner that does not entail uniqueness, hence the restriction to the and the bleached possessive.

CAPTURING THE DIFFERENT PARAPHRASES. The representation for a DP containing a nontemporal FA appears in 90, where we represent the denotation of the definite article with the iota operator.

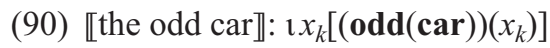

It follows directly from this semantics that we will not get the internal reading with nontemporal FAs. The internal reading arises, as shown above, when the FA intersectively modifies an internal event argument within the representation of a nominal. There is obviously no way for nontemporal FAs to achieve this kind of modification, as they crucially apply to descriptions of (kinds of) individuals, rather than to (kinds of) individuals themselves.

In contrast, the generic and adverbial readings can be straightforwardly accounted for in fundamentally the same way as they were accounted for with temporal FAs. The only difference is that the kind term contributed by the nominal containing a nontemporal FA is marked with the definite article and thus has a unique denotation. Thus, once the nominal's semantics has been composed, the rest of the semantics of the sentence can be composed in the same way as it was in the case of temporal FAs, modulo the fact that the kind variable in the denotation of the nominal is not available for binding, for instance, by a generic adverbial operator.

For example, 91b shows the representation for the generically used FA in 91a.

(91) a. The odd glitch is tolerable.

$$
\text { b. tolerable }\left(1 x_{k}\left[(\operatorname{odd}(\operatorname{glitch}))\left(x_{k}\right)\right]\right)
$$

In prose, $91 \mathrm{~b}$ states that the kind of thing that is a glitch, the members of whose set realization have a low distribution, is tolerable.

A representation for the generic reading involving coercion of the nominal appears in 92, analogous to that in 76 .

(92) a. The occasional beer is healthy. = V-ing a beer on an occasional basis is healthy.

b. healthy $\left(e_{k}\left[\mathbf{E}(\right.\right.$ occasional $($ beer $\left.\left.))\left(e_{k}\right)\right]\right)$

The representation in $92 \mathrm{~b}$ states that the kind of event that is a beer V-ing, realized by a set of events with a low distribution, is healthy.

Note that we now have an explanation for why the definite article appears with nontemporal FAs on the generic reading, even though the corresponding sentences without the FA were not interpreted generically: the article is present due to the uniqueness condition described at the end of the last subsection. Its presence is intimately connected to the contribution of the FA and is orthogonal to the genericity of the sentence as a whole.

Finally, we can account for sentences in which the FA can be given an adverbial paraphrase, such as 33a (repeated in 93a), which is represented as in 93b.

(93) a. The occasional sailor strolled by.

b. $\exists e_{k}\left[\right.$ strolled_by $\left(e_{k}, x_{k}\left[(\right.\right.$ occasional $($ sailor $\left.\left.\left.))\left(x_{k}\right)\right]\right)\right]$ 
The account of the specific entailments of $93 \mathrm{~b}$ is identical to that for sentences like 80 . The only difference is that the definite-kind description in 93a, unlike the indefinitekind description in 80 , picks out a necessarily unique kind.

Again, as was the case with temporal FAs, with one semantics we account for all 'readings' of the adjective. The different paraphrases are simply a by-product of other elements in the sentences in which they occur.

SOME COMMENTS ON THE PECULIARITIES OF THE NONTEMPORAL FAs. We close this section with some brief, speculative comments on the asymmetries between the temporal and nontemporal FAs. The first and perhaps most striking of these is the fact that temporal FAs are simple intersective predicates, while nontemporal FAs are necessarily predicate modifiers. We do not have an explanation for this asymmetry at this point; we can only hypothesize that it is related to the fact that temporal FAs have an alternative use as predicates of pluralities of token events, while nontemporal FAs lack any kind of basic predicative use related to distributions of token entities. More puzzling is the fact that temporal FAs ostensibly lack the predicate modifier use associated with their nontemporal counterparts. Given that we find nontemporal FAs in combination with all kinds of descriptions, including descriptions of event kinds, there would seem to be no logical reason why temporal FAs could not take on the predicate modifier use.

A second asymmetry has to do with the size and homogeneity of the classes. Though neither class is very large, the temporal FAs are rather more homogeneous than the nontemporal FAs, and the class clearly contains members expressing both high and low frequency, as well as fixed and variable frequency. With the exception of (in)frequent and (as far as we can determine) sporadic, they are all denominal, with a noun root identifying a unit of time with which a kind or set of eventualities can be related.

In contrast, previous literature has identified only three FAs that can be clearly identified as nontemporal—odd, rare, and (one use of) occasional - all of which express low frequency. Though all are amenable to the analysis developed in this section, each of these differs from the others in some respect. First, odd has a couple of seemingly different senses, one roughly synonymous with strange or unusual (as in an odd child), and the other with unmatched (as in an odd sock). These senses are not shared with the other FAs.

Second, rare (and rare only) has a variant as a two-place predicate expressing a relation between kinds and locations (recall the data in n. 20 and ex. 15, partially repeated in 94).

(94) a. That mosquito was rare (in these parts/ten years ago).

b. He was a rare contributor to Macmillan's.

Though clearly connected to its use as an FA, we have pointed out that this use is distinct from the use discussed in this article. To see this again in light of the analysis we have presented, consider 95 .

(95) The rare contributor to Macmillan's wrote about politics.

The domain over which rare expresses low distribution in this case is not related to events of writing, as would be expected if the adjective had the semantics proposed at the beginning of this section. Rather, it expresses low distribution of contributions to Macmillan's.

Finally, unlike odd and rare, occasional is denominal, and we have already noted that it can also be used as a temporal FA, while the other two cannot. In order to account for the broad use of occasional, we have hypothesized that it is ambiguous. It is now time to elaborate on this hypothesis. The careful reader will have noticed that we have said noth- 
ing so far about why occasional can appear with nonevent nouns accompanied by the indefinite article with an adverbial paraphrase, as in Bolinger's classic example, repeated in 96a. So far, what we have said would lead one to expect only the variant in $96 \mathrm{~b}$ to be acceptable with an adverbial paraphrase, particularly since $96 \mathrm{c}, \mathrm{d}$ are unacceptable.

(96) a. An occasional sailor strolled by.

b. The occasional sailor strolled by.

c. ??The sailors were occasional.

d. ??The sailor was occasional.

This expectation arises because we have associated the use of an indefinite article in adverbial paraphrases of FAs with a predicative semantics for the FA, and it happens that all such predicative uses (including with occasional) are sortally restricted to events.

We would like to suggest that Bolinger's classic example is indeed the exception, and not the rule. Though we must leave a detailed quantitative study for future research, a superficial examination of COCA reveals that the occasional occurs with about $45 \%$ more distinct nouns than does an occasional, indicating significantly greater productivity. ${ }^{34}$

There are various ways we could account for 96a. One is to assume that occasional is sortally unrestricted on both of its uses; on such an analysis, however, an explanation for the unacceptability of $96 \mathrm{c}, \mathrm{d}$ would be required. Alternatively, we could take an occasional to be a fixed expression in conjunction with sortal nouns. But this option is unattractive insofar as it fails to connect uses of occasional as in 96 with any of the other facts involving FAs that we have observed. Finally, the most interesting option, in our view, would be to try to connect these examples to the limited possibility of temporal FAs with sortal nouns mentioned toward the end of n. 18, and analyzed in detail in Gehrke \& McNally 2014, such as the examples in 97.

(97) a. She wrote frequent letters.

b. She baked frequent batches of cookies.

Perhaps the fact that the nontemporal FAs share only an entailment of low distribution, but arguably not the way in which that distribution is calculated or expressed, may help explain their peculiar and highly restricted morphosyntactic behavior as FAs, in comparison to temporal FAs.

One way to gain a deeper understanding into the asymmetries mentioned in this section and to arrive at a definitive analysis for examples like 96a would be to study when, how, and with which FA(s) the temporal vs. nontemporal and predicative vs. nonpredicative uses of FAs originated. For example, if the nontemporal use is a relatively recent innovation, it would not surprise us if it has extended so far by analogy only to other expressions expressing low frequency (and it may be that other adjectives expressing low frequency have uses that are susceptible to the same analysis, such as random or unusual). On the other hand, it has also been suggested to us by Itamar Francez (p.c.) that in fact other adjectives might recruit a similar semantics to express frequent, but not temporally defined, distribution. Candidates might include typical and usual, both of which appear with a similar use of the definite article.

(98) a. Yes there were the usual student antics ...

(GloWbE)

b. Sure, there were the typical Linus rants of the month ...

(GloWbE)

\footnotetext{
${ }^{34}$ Specifically, 994 noun lemmata are returned for an occasional $N$ vs. 1,450 for the occasional $N$. Note that these figures are intended to provide only a very rough idea of the frequency of each type of phrase. We have not yet divided these hits into event vs. participant vs. sortal nouns; many are event nouns and thus not relevant to the question at hand. We have also not yet checked the frequency with which sortal nouns in combination with an occasional have an adverbial paraphrase.
} 
Diachronic research could also tell us whether temporal FAs originated as predicates of pluralities of tokens and extended to a use as predicates of kinds, or vice versa. If the former turned out to be the case, we might have an explanation for why odd and rare fail to express distribution as simple predicates of pluralities. Learning how occasional was first used would surely help us understand the facts in 96.

The exploration of these possibilities will require detailed empirical study that we must leave for the future. However, we hope that what we have been able to document so far about these expressions will inspire interest in the question of why and how English (but, for example, not German or Spanish) developed the particular class of nontemporal FAs and how their use might be evolving.

4. Advantages over previous analyses. We are now in a position to point out the advantages of the analysis presented in the previous section over other analyses, which have been of two basic sorts. The first sort has treated the adverbial paraphrases of FAs by analyzing the FA essentially as a determiner, and thus as different from FAs that have been attributed internal or generic readings (which are not directly accounted for; see Stump 1981, Larson 1998, Zimmermann 2003). The second is a unified account for all readings of all FAs, pursued by Schäfer 2007 and Gehrke \& McNally 2011. The latter paper presents some arguments against the determiner analysis of adverbially interpreted FAs, as well as against the specific version of the analysis presented in Schäfer 2007; we do not review these arguments here. Rather, we focus on additional arguments against the determiner analysis and on showing how the recognition of the distinction between temporal and nontemporal distribution, missing in all previous proposals, solves a number of puzzles that have not been accounted for.

4.1. The DETERminer ANALYSis of THE ADVERBIAL READING. Let us first consider the determiner analysis. We use the analysis in Zimmermann 2003 to illustrate. Zimmermann argues that FAs under the adverbial reading syntactically incorporate into the determiner, as in 99 (Zimmermann 2003:271, minor details modified).

(99) $\left[\mathrm{IP}\left[\mathrm{QP}\left[\mathrm{Q} \text { the/an }+ \text { occasional }_{1}\right]\left[\mathrm{NP}_{1} t_{1} \text { sailor }\right]\right]_{2}\left[\mathrm{VP} t_{2}\right.\right.$ strolled by $]$

The result of incorporation is interpreted as a complex pluractional quantifier INFREQ over event-individual pairs that are found within a larger, contextually identified event (see 100a); the semantics for a sentence containing an INFREQ is presented informally in 100b (adapted from Zimmermann 2003:272, noncrucial details simplified).

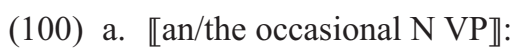

$\left(\mathbf{I N F R E Q}\langle e, x\rangle: \operatorname{part-of}\left(e, e^{*}\right) \wedge \mathbf{N}(x)\right)[\mathbf{V P}(e, x)]$

b. There are some pairs $\langle e, x\rangle$, with $e$ part of a contextually given event $e *$, and $x$ having property $\mathbf{N}$, such that $e$ is an event of $x$ VP-ing, and any two events of $x$ VP-ing occur at separate points in time.

The determiner analysis of the adverbial reading has been supported by two main sorts of arguments: the observation that the FA apparently scopes over the entire sentence, and the observation that the FA does not behave like a typical adjective in some respects. Gehrke \& McNally 2011 shows that the latter argument is not convincing; the reader is referred to that paper for details. Here, we show that there are scope facts that are in fact problematic for the determiner analysis.

UnEXPECTED SCOPE FACTS. A first, and quite significant, problem for the determiner analysis is posed by sentences that do not appear to be generic but rather involve the adverbial reading, and yet which do not permit a paraphrase in which the FA takes sentence-level scope. Normally, nothing prevents a quantifier in object position from 
taking scope over a sentence in which there is no other quantificational operator. However, consider 101.

(101) Idling beside the propped-open kitchen window he registers the occasional car swishing past, three stories below.

(COCA)

The syntactic analysis of this sentence is not trivial: it is not immediately obvious whether the occasional car swishing past should be analyzed as a DP or as a small clause. This is not important, however, because whichever analysis is chosen, there is no reason in principle why an INFREQ operator contributed by the FA (in conjunction with the determiner) should not be able to effectively scope over the entire sentence. Compare, for example, 102a, where the determiner many is substituted for the occasional. The crucial part of the sentence can be paraphrased as in either $102 \mathrm{~b}$ or 102c.

(102) a. Idling beside the propped-open kitchen window he registers many cars swishing past, three stories below.

b. There are many cars swishing past that he registers.

c. There are many cars such that he registers them swishing past.

The determiner analysis thus predicts that 101 should be paraphrased as in 103a or $103 \mathrm{~b}$, depending on the syntactic analysis one adopts.

(103) a. There are some pairs $\langle e, x\rangle$, with $e$ part of a contextually given event $e *$, and $x$ a car swishing past, such that $e$ is an event of him registering $x$, and any two events of him registering $x$ occur at separate points in time.

b. There are some pairs $\langle e, x\rangle$, with $e$ part of a contextually given event $e *$, and $x$ a car, such that $e$ is an event of him registering $x$ swishing past, and any two events of him registering $x$ swishing past occur at separate points in time.

Neither of these paraphrases is exactly right. The problem is that 101 entails that there are few cars swishing past, but neither of the informal representations in 103 carries this entailment. Rather, these representations only entail that there are few events of the subject referent registering the car (swishing past), and this could be the case if there are many cars (swishing past) and he simply fails to notice most of them. In other words, the effect of the FA appears to be only over events of swishing past, rather than over events of registering, but we see no independently motivated mechanism that could produce this effect, assuming the determiner analysis.

In contrast, these sorts of examples are not problematic for the analysis proposed here: they receive the same analysis as examples such as 93; contrast 104, where $y_{i}$ represents the pronoun he (we assume a small clause analysis for illustration).

(104) $\exists e, e_{k}\left[\operatorname{register}\left(e, y_{i}\right.\right.$, swishing_past $\left(e_{k}, x_{k}\left[(\right.\right.$ occasional $\left.\left.\left.\left.(\operatorname{car}))\left(x_{k}\right)\right]\right)\right)\right]$

The satisfaction conditions for this sentence will guarantee that the distribution of token cars is low; this, in turn, will guarantee that there are few token events of such cars swishing past. The sentence describes a token event of $y_{i}$ registering the kind of event that is one of the occasional car swishing past. This is exactly what we want.

UNEXPECTED DETERMINER FACTS. In addition to failing to explain these scope facts, the determiner analysis fails to provide an insightful account of the distribution of FAs with different determiners. In $\$ 2.1$ we noted that it has generally been assumed in the literature that the adverbial reading is only available with the (in)definite articles and semantically bleached possessives. Zimmermann proposes that this restriction can be accounted for at least in part on the hypothesis that the definite and indefinite articles are semantically empty. However, Gehrke \& McNally 2011 observes that treating these 
items as semantically empty and the FA essentially as a quantifier leaves unexplained why the FA must be accompanied by an overt article in the first place — that is, why 105 is unacceptable.

(105) *Occasional sailor strolled by.

The data we have presented here in fact weaken this account of the determiner restriction even further. We have shown here that previous work has failed to recognize the fact that there are really two patterns to the distribution of determiners with FAs, one for temporal and the other for nontemporal FAs, and that nontemporal FAs (and occasional on the nontemporal reading) are in fact restricted to the definite article and bleached possessive. The claim that the semantic emptiness of the articles underlies the determiner restriction is thus incorrect, and as a result the difficulty of explaining how the FA would contribute quantificational or referential force when there must also be a determiner doing so reemerges. Moreover, since the determiner analysis does not relate the generic and adverbial paraphrases, it has nothing to say about why any given FA shows a similar pattern of determiner restrictions on вотн the adverbial and generic readings.

UneXPeCted facts From German. Finally, recall from the discussion of 47 that Zimmermann claims that in German only FAs in subject but not in object position allow for the adverbial reading. He ties this in with the fact that German allows quantifier raising out of subject but not out of object position and takes this as an argument in favor of the determiner analysis of FAs. In further support of this claim, he notes that preposed topicalized objects, like the one in 106 (31 in Zimmermann 2003, also his nonliteral translation), are fine on the adverbial reading.

(106) Ein gelegentliches Bierchen haben wir auch getrunken. an.ACC occasional.ACC beer.DIM.ACC have we also drunk

'Of course, we have occasionally drunk a beer, too.'

Eight out of eleven of the native speakers we consulted agreed that this example is, in fact, acceptable. However, nine out of the eleven equally liked or even preferred 107 on the relevant reading, where the DP containing the FA remains in object position. The acceptability of this sentence on this reading is not predicted under Zimmermann's analysis.

(107) Wir tranken ein gelegentliches Bier. we drank an.ACC occasional.ACC beer.ACC

'We drank an occasional beer.' (= 'Occasionally, we drank a beer.')

Thus, these facts cannot be considered an argument for a determiner analysis of gelegentlich.

Summarizing, there are significant empirical challenges for the determiner analysis. Considering that it also requires positing syntactic movement that is not otherwise motivated and a nonstandard semantic type for the adjective to account for the adverbial paraphrases, we see no reason to maintain such an analysis.

4.2. ANALYSES THAT DO NOT DistingUish SUbCLASSES OF FAs. We now offer some final comments on the advantages of teasing apart temporal from nontemporal distribution. As noted throughout the article, a problem for all previous analyses of FAs is that they failed to observe this crucial distinction, which lies at the heart of the analysis proposed here. The result was that these analyses left various open questions, mentioned in Gehrke \& McNally 2011, to which we now have an answer. The most important of these were (i) why different FAs should manifest different determiner restrictions and (ii) why the different FAs vary in the paraphrases they admit depending on the sort of noun being modified. In addition, we have been able to link the distributional behavior 
of the two subclasses of FAs to another, previously unrecognized contrast between them, namely whether they allow a predicative use on the relevant reading. While an analysis that is not fully unified might be argued to lose something in elegance or simplicity, this loss is outweighed by considerable gains in empirical coverage. Moreover, the loss of uniformity is clearly anchored in lexical variation, where we might expect idiosyncrasy to lie. Finally, the crosslinguistic variation we observed-namely, the fact that German lacks the class of nontemporal FAs - lends further support to the division.

5. ConClusion. We have shown that FAs fall into two different subclasses depending on whether they effect temporal vs. nontemporal distribution. This new observation has led to an analysis that solves a number of puzzles that previous analyses failed to explain. We have argued that the interesting differences between the temporal and nontemporal FAs are attributable to the fact that the former are intersective modifiers sortally restricted to events, while the latter are not.

Though the analysis defended here does not present a fully unified treatment of FAs, it does provide a unified analysis of each individual FA, with the exception of occasional, which we have argued is ambiguous. The analysis thus preserves the spirit of unified analyses such as those in Schäfer 2007 and Gehrke \& McNally 2011 insofar as it avoids an ad hoc semantics for FAs in sentences where they can be paraphrased as sentential adverbs. It also reinforces the two most interesting theoretical proposals in the latter work, namely that sometimes kinds are crucially realized by sets of tokens, rather than individual tokens, and that some clauses constitute descriptions of event kinds, rather than descriptions of event tokens.

More generally, the study presented here opens up for further exploration a previously unrecognized strategy for conveying the sort of entailments typically analyzed in terms of quantification, namely distributional modification of kind descriptions. For example, one extension might include a reanalysis of so-called quantificational adverbs such as frequently or occasionally along similar lines, as predicates of event kinds described by clauses. The key to recognizing this possibility has been to focus on the fact that there is generally more than one way to analyze truth-conditionally equivalent sentences. FAs are a clear example of how the (no doubt natural) tendency to assign maximally similar representations to truth-conditionally equivalent sentences can be an obstacle to empirically adequate analysis and, more importantly, to the identification of theoretically important phenomena.

\section{REFERENCES}

Arsenijević, Boban; Gemma Boleda; Berit Gehrke; and Louise McNally. 2014. Ethnic adjectives are proper adjectives. Chicago Linguistic Society 46.17-30.

Asher, Nicholas. 2011. Lexical meaning in context. Cambridge: Cambridge University Press.

BARKER, CHRIS. 1999. Individuation and quantification. Linguistic Inquiry 30.683-91. DOI: $10.1162 / 002438999554264$.

BARwiSe, Jon, and RoBin COOPER. 1981. Generalized quantifiers and natural language. Linguistics and Philosophy 4.159-219. DOI: 10.1007/BF00350139.

Barwise, Jon, and John Perry. 1983. Situations and attitudes. Cambridge, MA: MIT Press.

Bolinger, Dwight. 1967. Adjectives in English: Attribution and predication. Lingua 18.1-34. DOI: 10.1016/0024-3841(67)90018-6.

Bouchard, Denis. 2005. Sériation des adjectifs dans le SN et formation de concepts. Recherches Linguistiques de Vincennes 34.125-42. Online: http://rlv.revues.org/1383.

CARLson, Gregory N. 1977. Reference to kinds in English. Amherst: University of Massachusetts, Amherst dissertation. [Published, New York: Garland, 1980.] 
Carlson, Gregory N. 1982. Generic terms and generic sentences. Journal of Philosophical Logic 11.145-81. DOI: 10.1007/BF00278382.

Carlson, Gregory N. 2009. Generics and concepts. Kinds, things, and stuff: Mass terms and generics, ed. by Francis Jeffry Pelletier, 16-35. Oxford: Oxford University Press.

Carlson, Gregory N., and Francis Jeffry Pelletier (eds.) 1995. The generic book. Chicago: University of Chicago Press.

Cinque, Guglielmo. 2010. The syntax of adjectives: A comparative study. Cambridge, MA: MIT Press.

Cohen, Ariel. 2001. On the generic use of indefinite singulars. Journal of Semantics 18. 183-209. DOI: $10.1093 /$ jos/18.3.183.

Dayal, Veneeta. 2004. Number marking and (in)definiteness in kind terms. Linguistics and Philosophy 27.393-450. DOI: 10.1023/B:LING.0000024420.80324.67.

DE SWART, HENRIËTTE. 1993. Adverbs of quantification: A generalized quantifier approach. New York: Garland.

Demonte, Violeta. 2008. Meaning-form correlations and adjective position in Spanish. Adjectives and adverbs: Syntax, semantics, and discourse, ed. by Louise McNally and Christopher Kennedy, 71-100. Oxford: Oxford University Press.

DÉPREZ, VIVIANE. 2005. Morphological number, semantic number and bare nouns. Lingua 115.857-83. DOI: 10.1016/j.lingua.2004.01.006.

Espinal, M. Teresa. 2010. Bare nominals in Catalan and Spanish: Their structure and meaning. Lingua 120.984-1009. DOI: 10.1016/j.lingua.2009.06.002.

Farkas, Donka F., and HenriëtTe De Swart. 2003. The semantics of incorporation: From argument structure to discourse transparency. Stanford, CA: CSLI Publications.

Farkas, Donka F., and Yoko Sugioka. 1983. Restrictive if/when clauses. Linguistics and Philosophy 6.225-58. DOI: 10.1007/BF00635644.

Gehrke, Berit. 2012. Passive states. Telicity, change, and state: A cross-categorial view of event structure, ed. by Violeta Demonte and Louise McNally, 185-211. Oxford: Oxford University Press.

GeHrKe, Berit. 2015. Adjectival participles, event kind modification and pseudo-incorporation. Natural Language and Linguistic Theory 33.897-938. DOI: 10.1007/s11049 -015-9295-7.

GehrKe, Berit, and Louise McNally. 2011. Frequency adjectives and assertions about event types. Proceedings of Semantics and Linguistic Theory (SALT) 19.180-97. DOI: $10.3765 /$ salt.v19i0.2523.

Gehrke, Berit, and Louise McNally. 2014. Event individuation by objects: Evidence from frequency adjectives. Proceedings of Sinn und Bedeutung 18.146-63. Online: http://semanticsarchive.net/sub2013/.

Ginzburg, Jonathan. 2005. Situation semantics: The ontological balance sheet. Research on Language and Computation 3.363-89. DOI: 10.1007/s11168-006-6329-7.

Greenberg, Yael. 2002. Two types of quantificational modalized genericity, and the interpetation of bare plurals and indefinite singular NPs. Proceedings of Semantics and Linguistic Theory (SALT) 12.104-23. DOI: 10.3765/salt.v12i0.2871.

Gupta, ANIL. 1980. The logic of common nouns: An investigation into quantified modal logic. New Haven, CT: Yale University Press.

KeEnan, Edward, and Jonathan Stavi. 1986. A semantic characterization of natural language determiners. Linguistics and Philosophy 9.253-326. DOI: 10.1007/BF00630 273.

Kratzer, Angelika. 1998. Scope or pseudoscope? Are there wide scope indefinites? Events and grammar, ed. by Susan Rothstein, 163-96. Dordrecht: Kluwer.

KrifKa, MANFRED. 2013. Definitional generics. In Mari et al., 372-89.

Krifka, Manfred; Francis Jeffrry Pelletier; Gregory N. Carlson; Alice ter Meulen; Gennaro Chierchia; and Godehard Link. 1995. Genericity: An introduction. In Carlson \& Pelletier, 1-125.

Landman, Meredith, and Marcin Morzycki. 2003. Event-kinds and the representation of manner. Western Conference on Linguistics (WECOL) 14.136-47. Online: http://www.fresnostate.edu/artshum/linguistics/wecolproceedings.html.

Larson, Richard. 1998. Events and modification in nominals. Proceedings of Semantics and Linguistic Theory (SALT) 8.145-68. DOI: 10.3765/salt.v8i0.2803. 
Mari, Alda; Claire Beyssade; and Fabio del Prete (eds.) 2013. Genericity. Oxford: Oxford University Press.

McNally, Louise. 1992. An interpretation for the English existential construction. Santa Cruz: University of California, Santa Cruz dissertation. [Published, New York: Garland, 1997.]

McNALly, LoUISE. 1998. Existential sentences without existential quantification. Linguistics and Philosophy 21.353-92. DOI: 10.1023/A:1005389330615.

McNally, Louise, and Gemma Boleda. 2004. Relational adjectives as properties of kinds. Empirical Issues in Syntax and Semantics 5.179-96. Online: http://www.cssp.cnrs.fr /eiss $5 /$ monally-boleda/index.html.

MiLsark, GARY. 1974. Existential sentences in English. Cambridge, MA: MIT dissertation. [Published, New York: Garland, 1979.]

Moltmann, Friederike. 1997. Parts and wholes in semantics. Oxford: Oxford University Press.

Mueller-Reichau, Olav. 2011. Sorting the world: On the relevance of the kindlevel/object-level distinction to referential semantics. Frankfurt: Ontos.

Potts, Christopher. 2005. The logic of conventional implicatures. Oxford: Oxford University Press.

Pustejovsky, James. 1995. The generative lexicon. Cambridge, MA: MIT Press.

ReInhart, TANya. 1997. Quantifier scope: How labor is divided between QR and choice functions. Linguistics and Philosophy 20.335-97. DOI: 10.1023/A:1005349801431.

SAILER, MANFrED. 2010. The family of English cognate object constructions. Proceedings of the 17th International Conference on Head-Driven Phrase Structure Grammar (HPSG 2010), 191-211. Online: http://cslipublications.stanford.edu/HPSG/2010/sailer .pdf.

SchäFer, Roland. 2007. On frequency adjectives. Proceedings of Sinn und Bedeutung 11.555-67. Online: http://parles.upf.edu/llocs/glif/pub/sub11/individual/schaefer.pdf.

Strawson, Peter F. 1959. Individuals: An essay in descriptive metaphysics. London: Routledge.

Stump, Gregory T. 1981. The interpretation of frequency adjectives. Linguistics and Philosophy 4.221-57. DOI: 10.1007/BF00350140.

Svenonius, Peter. 2008. The position of adjectives and other phrasal modifiers in the decomposition of DP. Adjectives and adverbs: Syntax, semantics, and discourse, ed. by Louise McNally and Christopher Kennedy, 16-42. Oxford: Oxford University Press.

Winter, Yoad, and Joost Zwarts. 2012. On the event semantics of nominals - the oneargument hypothesis. Proceedings of Sinn und Bedeutung 16.2.639-46.

ZAMPARELLI, RoBerTo. 1995. Layers in the determiner phrase. Rochester: University of Rochester dissertation. [Published, New York: Garland, 2000.]

Zimmermann, Malte. 2003. Pluractionality and complex quantifier formation. Natural Language Semantics 11.249-87. DOI: 10.1023/A:1024937316555.

Gehrke

Laboratoire de Linguistique Formelle

UMR 7110, CNRS/Université Paris Diderot

Case Postale 7031

5 , rue Thomas Mann

F-75205 Paris cedex 13, France

[berit.gehrke@1inguist.univ-paris-diderot.fr]

\section{McNally}

Departament de Traducció i Ciències del Llenguatge

Universitat Pompeu Fabra

c/Roc Boronat, 138

E-08018 Barcelona, Spain

[louise.mcnally@upf.edu]
[Received 5 September 2012; revision invited 17 June 2013; revision received 29 December 2013; accepted 27 July 2014] 